\title{
EL CARDENAL JOAN LLOPIS, POLÍTICA Y MECENAZGO AL SERVICIO DE LOS BORJA (1454-1501)*
}

\author{
POR \\ Álvaro Fernández de Córdova Miralles ${ }^{1}$ \\ Universidad de Navarra
}

\begin{abstract}
RESUMEN
El presente trabajo analiza la actividad política y cultural del valenciano Joan Llopis, secretario de Rodrigo de Borja (futuro Alejandro VI) y uno de sus cardenales más afectos durante su pontificado. Gracias a su destreza y discreción, ocupó el oficio de la dataría convirtiéndose en uno de los principales colaboradores del papa en el gobierno de la Iglesia y sus relaciones con los Reyes Católicos, Florencia y el reino de Nápoles, sin abandonarle en los años finales de aproximación a Francia. Desde su privilegiada posición, Llopis participó en los círculos intelectuales romanos e impulsó proyectos artísticos en Perugia y la Ciudad Eterna que reflejan su sensibilidad por las corrientes culturales del Renacimiento. Aunque la acumulación de beneficios le acarrearon acusaciones de corrupción, Llopis no consolidó un patrimonio familiar, dedicando vida y ganancias a un papado al que sirvió en uno de los períodos más polémicos de su historia.
\end{abstract}

PALABRAS CLAVE: Joan Llopis; Alejandro VI; corte pontificia; mecenazgo artístico; humanismo.

\section{CARDINAL JOAN LLOPIS, POLITICS AND PATRONAGE IN THE SERVICE OF THE BORGIAS (1454-1501)}

\begin{abstract}
This paper analyzes the political and cultural activity of the Valencian Joan Llopis, who was secretary of Rodrigo Borgia - later Pope Alexander $\mathrm{VI}$ - and was one of the most favoured cardinals during that pontificate. Thanks to his skill and discretion, he held the office of the Dataria, and became one of the principal collaborators of the Pope in the government of the Church and its relations with the Catholic Monarchs, as well as Florence and the kingdom of Naples, without abandoning the Pope as he later gravitated towards France. From his privileged position, Llopis frequented Roman intellectual circles and commissioned works of art in Perugia and Rome that reflect his sensitivity to the cultural currents of the Renaissance. Although his accumulation of benefices prompted accusations of corruption, Llopis did not build up a family inheritance, but devoted his life and earnings to the papacy, which he served during one of the most controversial periods in its history.
\end{abstract}

KEY WORDS: Joan Llopis; Alexander VI; Papal Court; patronage; Renaissance humanism.

Cómo CitAR ESTE ARTículo / CitATION: Fernández de Córdova Miralles, Á. 2017. «El cardenal Joan Llopis, política y mecenazgo al servicio de los Borja (1454-1501)». Hispania Sacra 69, 139: 133-148. doi: 10.3989/hs.2017.009

Recibido/Received 18-08-2014

Aceptado/Accepted 10-09-2014

\section{INTRODUCCIÓN ${ }^{1}$}

Los estudios prosopográficos impulsados en las últimas décadas sobre las clientelas valencianas del siglo XV han

${ }^{*}$ Agradezco a Miguel Navarro Sorní, José María Cruselles, María Toldrà, José María Fernández de Córdova y Andrew Soane sus indicaciones, aportaciones documentales y correcciones que han mejorado el texto.

1 afdecordova@unav.es / ORCID iD: http://orcid.org/0000-00029435-6387 permitido reconstruir las trayectorias de algunos importantes eclesiásticos que prosperaron a la sombra de Calixto III y Alejandro VI. ${ }^{2}$ Con ello se ha logrado conocer mejor la vida de estos hombres encaramados al poder papal y analizar las vías de promoción en su vertiente eclesiástica, política, económica y social. La elección pontificia de Calixto III ofreció una extraordinaria plataforma de ascenso para una serie de familias valencianas que aprovecharon los cargos curiales

2 Pons Alós y Cárcel Ortí 2001 y 2005; Pons Alós 2005; Vaquero Piñeiro 2001; Cruselles Gómez 2001; Cruselles Gómez e Iradiel 2001. 
para aumentar sus redes de influencia y ampliar el patrimonio familiar en el triángulo mediterráneo formado por Nápoles, Valencia y la Ciudad Eterna. No se trataba de un fenómeno unidireccional -de la periferia al centro- pues respondía igualmente a la dinámica cortesana de la Curia papal que seleccionaba su personal a través de los vínculos de parentesco con la familia del pontífice reinante y entre las familias cardenalicias, estableciéndose una relación de reciprocidad entre señores y servidores basada en la amistad y las prácticas de favor que conducía a la formación de grupos clientelares. ${ }^{3}$ Estas redes sociales podían extenderse a las comunidades nacionales asentadas en Roma, como la natio hispana que reunía a castellanos y catalano-aragoneses, ${ }^{4}$ o establecer vínculos con los ambientes comerciales, diplomáticos e intelectuales de la Urbe. ${ }^{5}$

El caso de Rodrigo de Borja y Lluís Joan del Milà, sobrinos del primer papa Borja, constituyen los ejemplos más significativos de la primera generación de valencianos que, a la sombra de su tío, lograron ascender al colegio cardenalicio y, en el primer caso, ocupar la sede papal. ${ }^{6}$ La segunda generación de españoles que sirvieron a Alejandro VI no pudieron desplegar, sin embargo, las mismas estrategias promocionales al ver ampliamente recortadas sus posibilidades de medro familiar o de representar los intereses de las oligarquías locales de las que procedían, ${ }^{7}$ desde el momento en que sus fuentes de subsistencia y espacios de acción dependieron casi exclusivamente de la sola voluntad papal, que lograba de este modo garantizar su independencia en una Roma sometida a fuertes tensiones internacionales.

Uno de los ejemplos mejor conocidos es el de la familia valenciana de los Llopis estudiada por José María Cruselles Gómez en excelentes trabajos centrados en los vínculos que trabó con las clientelas borgianas a través de sus propias relaciones de servicio y parentesco. Esta investigación ha logrado reconstruir sobre bases documentales los orígenes y la promoción eclesiástica de uno de sus miembros más eminentes, Joan Llopis, que acabó siendo el hombre clave del pontificado de Alejandro $\mathrm{VI}^{8}{ }^{8}$ Su meteórica trayectoria desde el cargo de secretario de Rodrigo de Borja a cardenal de la Iglesia y consejero de la mayor confianza del papa constituye un singular caso de ascenso desde las clases medias valencianas a las

3 Mozzarelli (ed.) 1988; Fragnito 1993; Signorotto y Visceglia (ed.) 1998; Visceglia 2008: 87-88.

4 Fernández Alonso 1956; Vaquero Piñeiro 1993 y 1994; Serio 2003; López Arandia 2005.

5 Amplia bibliografía y algunos casos concretos en Salvador Miguel 2012; Fernández de Córdova 2014a.

6 Sobre Lluís Joan del Milà cfr. Fernández de Córdova Miralles 2013a. Sobre Rodrigo de Borja remitimos a Navarro Sorní y Fernández de Córdova Miralles 2009; y a los excelentes repertorios bibliográficos recogidos por el Institut Internacional d'Estudis Borgians (www. elsborja.org). php].

7 Cruselles Gómez 2008-2009 [http://www.elsborja.org/revista.

8 Los principales trabajos del autor sobre los Llopis son: Cruselles Gómez 1986, 1992a, 1992b: 157-158 y 1998; Cruselles Gómez e Igual Luis 2005. Sobre el cardenal Joan Llopis es preciso acudir a los trabajos específicos de Cruselles Gómez 1995 y 1997; y Cruselles Gómez y Navarro Sorní 2012. Además de los datos proporcionados por Sanchís Sivera y Pascual i Beltrán, debemos acudir a las antiguas semblanzas de Chacón 1677, III: 186; Cardella 1793, III: 272-273; Moroni 1843, 19: 132; AA. VV. 1936: 119. Y la entrada más moderna de Goñi Gaztambide 1987. Las breves y precisas notas de Maria Toldrà en Woodward 2005: 346; Fernández de Córdova Miralles 2005a: 99-102. cotas más altas de la Curia, aunque -a diferencia de la generación anterior- no gozará de las mismas posibilidades para aumentar el patrimonio familiar.

A pesar de los progresos historiográficos apuntados, no resulta fácil conocer con precisión el itinerario de estos eclesiásticos que han dejado su huella en despachos diplomáticos, bulas y breves pontificios, epistolarios, diarios, crónicas, monumentos artísticos y obras literarias. Joan Llopis es uno de estos versátiles personajes que cuenta con una carrera particularmente sugestiva desde el punto de vista eclesiástico, político y artístico, gracias a las relaciones que cultivó y al poder ejercido como confidente del papa. El objetivo de este artículo es abordar su polifacética actividad recorriendo su itinerario biográfico gracias a la información dispersa en fuentes publicadas y documentación de archivos españoles e italianos que no ha sido utilizada hasta ahora. A la luz de estas fuentes emerge una figura ejemplar de las redes sociales y de poder que permite esclarecer las formas de promoción y servicio en la Corte romana a comienzos de la modernidad.

\section{PROMOCIÓN ECLESIÁSTICA Y CONTACTOS INTELECTUALES (1454-1491)}

Joan Llopis pertenecía a una familia de notarios valencianos que había prosperado al servicio de la monarquía entre finales del siglo XIV y principios del XV. Su padre Antoni Llopis hizo un par de viajes a Sicilia junto a su maestro, el notario Joan Marromà, que ejercía como subsíndico del municipio valenciano, para gestionar asuntos de la ciudad en la corte real. Después Antoni acabó ocupándose de la escribanía de la Gobernación en la ciudad del Turia. Tras un primer matrimonio con la hija del mercader Bernat Cerdà casó con Agnés -hija del difunto notario Nicolau Menor- de la que tuvo once hijos, siendo sólo seis los que alcanzaron la edad adulta. Joan había nacido el 27 de enero de 1454 y era segundogénito pero la incapacidad del hermano mayor, víctima de una enfermedad contraída durante la adolescencia, lo convirtió en pieza central del proyecto familiar de su padre, que orientó al joven y a su hermano Jeroni hacia la Iglesia y la práctica burocrática, en consonancia con la tradición de una parentela abundantemente surtida de notarios, abogados y clérigos. ${ }^{9}$

Juan recibió la tonsura en 1462 a los nueve años, después de que su padre le hubiera facilitado algunos beneficios en la iglesia de San Nicolás, el Monasterio de San Vicente y la parroquia de Santa Catalina. ${ }^{10}$ En un confortable ambiente presidido por la figura paterna y frecuentado por juristas y eclesiásticos, los dos hermanos recibieron sus primeras letras de su preceptor doméstico Francesc Gacet -estudiante de artes al menos desde 1468- que les acompañó a Bolonia en 1470 para realizar estudios de teología en el caso de Joan, y derecho en el de Jeroni. ${ }^{11}$ En el verano de 1472, Antoni barajó la posibilidad de enviar a París a Joan, al amparo de dos clérigos valencianos que estudiaban allí, pero finalmente permaneció en Bolonia. ${ }^{12}$ Las estrechas relaciones que el padre mantenía con las familias Jàfer y Montsoriu, titulares

9 Cruselles Gómez 1995: 230-231; Cruselles Gómez y Navarro Sorní 2012: 252.

10 Pons Alós y Cárcel Ortí 2005: 938.

11 Cruselles Gómez 1992b: 158 y ss; 1995: 229 y ss.

12 Cruselles Gómez 1995: 235. 
del dominio útil de la escribanía de la Gobernación, sirvieron para poner al hijo bajo la protección del vicecanciller Rodrigo de Borja. En el verano de 1474, una vez obtenido el bachillerato en Teología, marchó a Roma provisto con una carta de recomendación firmada por Beatriz de Borja -hermana del vicecanciller- y dirigida al secretario del cardenal, Bartomeu Vallescar, quien se ocuparía de él durante sus primeros años romanos como familiar del vicecanciller. En la Ciudad Eterna debió recibir lecciones del teólogo Fernando de Córdoba y estrechó relaciones con intelectuales y humanistas como Paolo Pompilio y Jeroni Pau, quien le describe en su De viris illustribus (1475) como valenciano «que sobrepasa las fuerzas de la juventud con la importancia de su talento y de sus gloriosas costumbres». ${ }^{13}$ Mientras tanto Jeroni continuaba sus estudios en Bolonia junto su preceptor Francesc Gasset, e igualmente relacionado con Jeroni Pau que le cita entre sus dulcissimis amicis en agosto de $1475 .^{14}$

De sus años en la corte cardenalicia dan cuenta cuatro cartas remitidas al padre en 1476 . En este año la familia atravesó dificultades económicas que hicieron peligrar el futuro de Joan, incapaz de hacerse un hueco en la cancillería papal a causa de la feroz competencia en la compra de oficios. No obstante, en una carta dirigida a su padre, contaba la confianza y el afecto que le dispensaba el cardenal, compartiendo viajes y cacerías o concelebrando la Misa en ausencia de Vallescar. ${ }^{15}$ En una ocasión se permitió incluso solicitar a su padre dos lanzas, dos perros de caza y cinco arcos, éstos últimos para agasajar a su patrono. ${ }^{16}$

Ignoramos en qué fecha fue nombrado secretario del vicecanciller Rodrigo de Borja, pero en diciembre de 1476 Joan se sentía con la suficiente seguridad para apoyar la carrera curial de Francesc Gasset, mientras su hermano Jeroni regresaba a Valencia tras finalizar sus estudios en Bolonia y en Pisa. ${ }^{17}$ Dos años después Joan obtuvo su primer beneficio eclesiástico relevante con la concesión del Préstamo de Alicante, al que añadió al año siguiente la rectoría del Valle de Seta, una rectoría en Torrente (18.VI.1482), una iglesia parroquial en la diócesis de Valencia (10.VII.1482), una canonjía en la sede valentina (30.IV.1484) y otra en Lérida (8.II.1484); finalmente, recibió en 1486 la dignidad de deán de la Seo valenciana -que disfrutaba desde 1480- y el vicariato de la parroquia de San Juan del Mercado. ${ }^{18}$ Cargos todos ellos que arrendaba a través de su padre o su hermano y le proporcionaban una cantidad de dinero a la que se añadían las propinas recibidas como abbreviatore di parco minore, oficio que ocupaba al menos desde 1479 con otros familiares valencianos o catalanes, como Jaume Casanova, Jeroni Pau o Joan de Borja y Navarro. ${ }^{19}$ Con este título asistió al cónclave de 1484 acompañando a su protector, y recibió del colegio cardenalicio el encargo de redactar y copiar las capitulaciones del cónclave con otros dos abreviadores.

13 Vilallonga 1986, I: 46, 61, 83, 98, 100, 109 y 121.

14 Sobre Francesc Gasset véanse las notas biográficas de Cruselles Gómez. 1995: 245-246; y de Maria Toldrà en Gregorovius 2008: 61, 74 y ss. Sobre la relación de Jeroni Llopis y Jeroni Pau cfr. Vilallonga 1986, I: 83

15 Cruselles Gómez 1995: 240-241.

16 Cruselles Gomez 1997: 398-399.

17 Cruselles Gómez 1992b: 158 y ss.

18 Pons Alós y Cárcel Ortí. 2005: 938.

19 Frenz 1989: 378; Partner 1990: 239; Cruselles Gómez 1995: 214-242.
Como se ha indicado, Jeroni no acompañó a su hermano a Roma. Tras doctorarse en ambos derechos en Bolonia, regresó a Valencia en $1478,{ }^{20}$ sin perder sus vínculos con el vicecanciller, de quien recibía desde 1487 un salario de mil quinientos sueldos anuales por administrar el ducado de Gandía en representación de Joan de Borja, heredero del linaje desde el fallecimiento del primogénito Pere Lluis en 1488. Con la colaboración de su hermano, Jeroni fue elegido tutor del nuevo duque de Gandía encargándose del traspaso de la herencia, e interviniendo en los acuerdos matrimoniales de Lucrecia Borja, hija del vicecanciller. Durante estos años, ejerció algunos cargos municipales y -a diferencia de su hermano- dio a su vida una orientación secular obteniendo el rango de caballero y siendo elegido en 1490 jurado de la ciudad por el brazo militar. Los registros vaticanos datados el 10 de marzo de 1500 atestiguan su casamiento con Damieta de Loris, de la que tuvo al menos cuatro o cinco hijos. ${ }^{21}$

Sus aspiraciones no se redujeron a los límites de la oligarquía valenciana, pues pertenecía al nuevo grupo de universitarios expertos en leyes capaces de satisfacer las necesidades del poder político al más alto nivel, incluido el diplomático. Beneficiándose del ascendiente de su patrono ante Inocencio VIII, fue enviado a Francia para tratar probablemente las reivindicaciones napolitanas de Carlos VIII, «de cuya ida se tuvo por cierto que no resultaron buenos efectos en favor del rey de Nápoles», Fernando I o Ferrante I, perteneciente a la dinastía aragonesa. ${ }^{22}$ En 1486 el propio Ferrante le envió a Roma con Giovanni Gagliano para tratar una concordia con el papa y los embajadores castellanos en agosto de aquel año. Más tarde Inocencio VIII volvió a enviarlo a Hungría, como recuerda Paolo Pompilio.

Mientras tanto, Joan no se movió de Roma. Paradigma del clérigo cortesano de la época, practicó siempre un absentismo de sus beneficios valencianos que gestionaban su padre y su hermano, mientras él se entregaba en cuerpo y alma a los negocios del vicecanciller. En 1488 firmó como notario apostólico en el testamento de su primogénito Pere Lluis de Borja (14.VIII.1488), y un mes después eligiendo los tutores que debían representar nuevo duque de Gandía, Joan de Borja, en Valencia. ${ }^{23}$ Entre sus compromisos formativos se le adjudicó la elección de los maestros de César Borja, escogiendo en 1488 al joven académico Paolo Pompilio como maestro de gramática. ${ }^{24} \mathrm{Su}$ influencia había crecido tanto que -según este humanista- se había convertido en un nuevo Hércules ayudando a Atlas [el vicecanciller] a sostener la bóveda del cielo en el gobierno de la Curia y la relación con los príncipes. Por ello escribe: "tú le sustituyes cuando está cansado, tú recibes todo el peso sobre tus firmes espaldas [...] y lo haces con tanta seguridad como buen ánimo, mientras el mismo príncipe se alegra y más confía en ti». Lo demuestra su carrera beneficial auspiciada por su patrono: en 1491 recibió la Almosnería de Zaragoza pero renunció a la abadía riojana de Valbanera para complacer al rey Fernando de Aragón; y en

20 Se reconstruye su itinerario en Cruselles Gomez 1997: 395-399.

21 Archivio Secreto Vaticano (Ciudad del Vaticano) [a partir de ahora ASV], Reg. Vat. 882, ff. 488v-491r (485v-488r); cfr. Ilari 2001, I: 290; Grafinger 2002, II: 26-27.

22 Alfonso Chacón (1677: 186) considera a Jeroni «nuncii apostolici in Gallia»; Zurita 1977, VIII: 184 y 512-513.

23 Sanchís Sivera 1919: 14 y 17.

24 Bracke 2002: 430-432 y 435. 
la Curia fue promovido con una canonjía en la basílica de San Pedro y el nombramiento de secretario del colegio cardenalicio con 8.400 sueldos anuales.

Sus intervenciones en el registro de protocolos del notario Camillo Beneimbene reflejan su pericia jurídica y competencia lingüística en latín y catalán a la hora de redactar estos documentos jurídico-matrimoniales ${ }^{25}$ Su primera intervención data de 1486 en que firma como como testigo en los acuerdos del vicecanciller con Gabriele Cesarini sobre la dote de Jerònima de Borja (3.VI.1486 y 19.II.1489). ${ }^{26}$ Más adelante intervendría en los pactos matrimoniales de Lucrecia Borja con Querubí Joan de Centelles (19.Il.1491 y 16.VI.1491) y con Gaspar de Pròxida, hijo del conde de Almenara (24.III.1492 y 8.XI.1492). ${ }^{27}$

No se trataba de un prestigio meramente técnico, pues el humanista y gramático Paolo Pompilio (1455-1491) -miembro de la academia romana y profesor del Studium Urbis- le dedicó su Vita Senecae en $1490 .{ }^{28}$ Como señala en el prólogo, Pompilio ofrecía su obra a los dos hermanos Llopis ponderando el splendor y la honestissima generositas de la familia y solicitando a Joan, habitual lector de sus escritos, que revise y enmiende cualquier error del texto. Como philosophum et sacrae theologiae religiosissimum assertorem, nuestro protagonista contaba con la preparación suficiente para valorar esta investigación histórico-filológica que había sido auspiciada por Pomponio Leto-director de la Academia Romana-, y se la considera particularmente valiosa por la acribia en el tratamiento de la obra del filósofo cordobés. ${ }^{29}$ La Vita Senecae, se inserta además en un marco celebrativo de España y de los personajes ilustres que desde la Antigüedad habían nacido allí; una línea argumentativa que unía España y Roma y había sido desarrollada con diferentes énfasis por Rodrigo Sánchez de Arévalo y Joan Margarit i Pau, recibiendo en la década de 1480 el formidable impulso de otros curiales ibéricos e italianos al compás de las victorias de la guerra de Granada y el creciente prestigio de la monarquía hispánica. ${ }^{30}$ Llopis se situaba así entre los promotores de una Antigüedad rescatada y proyectada sobre la palpitante actualidad política.

Más dudosa es la identificación propuesta por Faider de nuestro protagonista con el Johannes Lopis de Ayora, doctor en medicina y teología, originario de Valencia que se doctoró en artes y medicina el 10 de octubre de $1497^{31}$ y es autor del Speculum aureum formalitatum Scoti (Siena, ed. Henricus de Harlem, 1492), obra filosófico-científica que figuraba en la biblioteca de Pico della Mirandola ${ }^{32}$ y se editó posteriormente en Nápoles con una dedicatoria al arzobispo Jiménez

25 Parisi 2006-2007: 221 y 223. Véase la reciente y cuidada edición Parisi 2015: 25.

26 Parisi 2015: 109-113.

27 Parisi 2015: 130-157.

28 La obra fue editada en Roma por Eucharius Silber el 16 de febrero de 1490, y tuvo una sucesiva edición a cargo de Ricardo Pafraet entre 1491 y 1497; una copia de ésta, con anotaciones manuscritas del siglo XVI, en Real Academia de la Historia (Madrid), Inc. 128; cfr. Faider 1921; Bracke 2002: 430-432 y 435.

29 Gualdo Rosa 2009: 27-28.

30 Tratamos este tema en los siguientes trabajos complementarios: Fernández de Córdova Miralles 2005b, 2007b y 2014b. El profesor Nicasio Salvador Miguel desarrolla en la actualidad una minuciosa investigación sobre los ecos romanos de la guerra de Granada. Véase su sugerente aproximación Salvador Miguel 2012: 47-64.

31 Minnucci 1981: 42-43; Minnucci y Kosŭta 1989: 260.

32 Kibre 1936: 83; Benavent 2005: 163 y 2007: 141-149. de Cisneros..$^{33} \mathrm{Y}$ tampoco debe confundirse con Juan López de Segovia, decanus segobiensis, protonotario apostólico y reputado canonista enterrado en la iglesia de Santa Maria del Popolo. ${ }^{34}$

\section{UN LOBO HISPANO EN LA DATARÍA APOSTÓLICA (1492-1495)}

El momento culminante de su carrera tuvo lugar el 6 de agosto de 1492: Joan entró como asistente del cardenal Borja en un cónclave del que salió como datario del recién elegido Alejandro VI. Se trataba de un oficio considerado oculus papae por las amplias prerrogativas que tenía en la concesión de gracias in foro externo debido a su conexión con la Signatura de Gracia. ${ }^{35}$ Durante este pontificado, el cargo incrementó sus atribuciones ejerciendo una indiscutida autoridad en el oficio del Registro, controlando las súplicas dirigidas al pontífice y gestionando las gracias papales. ${ }^{36}$ Se explica que el proyecto de reforma impulsado en 1497 prescribiera que el oficio se entregara a "hombre muy justo de buena vida y buena consciencia, porque non pueda seyer contaminado». ${ }^{37}$ Afirmación que se entiende a la luz de los epigramas satíricos que denunciaban la corrupción de los datarios de Alejandro VI, que han devastado la Curia por su falta de escrúpulos expresada en sus propios nombres que asocian a Llopis con el "lobo" (lupus), a Giovanni Battista Ferrari con el "hierro" (ferro) y Juan Ortega con la "ortiga" (urtica). ${ }^{38}$

Cuatro meses después de la elección de Alejandro VI, Joan recibió la sede de Perugia (29.XII.1492) sin perder sus beneficios anteriores, y tras el fallecimiento del célebre notario Gaspare Biondo fue nombrado secretario del papa (23. XII.1493), permitiéndole intervenir en los asuntos domésticos y en las maniobras más delicadas de la política pontificia. Con Joan Marrades y Pedro Carranza, se había convertido en uno de los familiares más próximos a Alejandro VI en un momento en que empezaban a detectarse inquietantes deserciones en el colegio cardenalicio. ${ }^{39}$ De ahí que algunos testimonios adversos le describan junto a otros curiales hispanos (Francisco Troche, Joan Marrades y Jaume Casanova) riendo la astucia de Alejandro VI que se desentendía como pontífice de las promesas hechas como vicecanciller. ${ }^{40}$

33 Probablemente se trate del Joannem Lopis Valentinum de Ayora, lector de física y metafísica de Nápoles (1507-1510), que figura como autor de un Viridarium virtutum (1504-1506) dedicado a Fernando el Católico, y editado en Nápoles por Segismundo Mayr el 10 de junio de 1509. Una versión manuscrita y miniada se conserva en Bibliothèque et Archives du Château de Chantilly, Ms. 300.

34 Tubau 2010. Su epitafio en Archivo de la Corona de Aragón, Ms. Sant Cugat, 84 (agradezco a María Toldrà esta indicación).

35 Para hacerse una idea de la importancia del oficio de datario baste citar el siguiente informe del embajador veneciano referido a Alejandro VI: «il papa de iure non può nulla; anzi due cardinali deputati, se loro non paiono giuste, possono stracciare le bolle che fa il Papa, e così fa pure il Datario"; en Albèri (ed.) 1846, III: 12. Sobre el cargo cfr. Célier 1910: 56-59; Storti 1969; Partner 2003: 31-32

36 Storti 1969: 61-69 y 143-148.

37 Ibídem: cap. 275

38 «Immiti laniata lupo, transfixaque ferro / Sanari Urtica, credula Roma putas? // Passa lupi dentes dirumque in viscera ferrum / Urtice stimulos ne tibi Roma time»; Burckardt 1907-1942, II: 333 . Véanse también las consideraciones de Pellegrini 2002b: 21-22.

39 Clement 1882: 27.

40 Altieri 1995: 186. 
La mano de Llopis se advierte en la primera maniobra diplomática de Alejandro VI al trenzar una alianza antinapolitana con Venecia, Florencia y el Milán de los Sforza concertando el matrimonio de su hija Lucrecia con Giovani Sforza, señor de Pesaro (2.II.1493). ${ }^{41}$ En noviembre de 1492 Alejandro VI pensó en enviarle a Francia pero, a los pocos meses, le implicó en el proyecto de alianza con la Casa de Aragón mediante el matrimonio del duque de Gandía y María Enríquez, hija de Enrique Enríquez, mayordomo del rey Fernando. Para facilitar el enlace y desmentir los informes negativos sobre el pontífice, el datario envió a su futuro yerno una apasionada apología de Alejandro VI que resaltaba su ingenio y experiencia, su justicia y clemencia en el gobierno de la Iglesia, su devoción en los asuntos religiosos y su liberalidad en las obras de mecenazgo emprendidas en Roma (28.III.1493). ${ }^{42}$ Mientras tanto Isabel de Castilla y Fernando de Aragón solicitaron su ayuda para resolver asuntos relacionados con beneficios, rentas o la reforma de ciertos monasterios. ${ }^{43}$ Llopis también contribuyó a pacificar las tormentosas relaciones del papa con Ferrante de Nápoles. En enero de 1493, el monarca le agradeció «la bona opera se fa per ipso in omne cosa», prometiendo recompensarle, y meses después recurrió nuevamente a sus servicios para impugnar los escritos antipapales que se le atribuían, y favorecer el enlace de su familia con la del pontífice. ${ }^{44}$

El 19 junio de 1493 Llopis pronunció el discurso de recibimiento a la embajada enviada por los reyes de Castilla y Aragón para prestar obediencia al pontífice y apartarle de la alianza franco-milanesa dirigida contra la dinastía aragonesa de Nápoles. ${ }^{45}$ El datario se esforzó por desactivar al principal agente de esta coalición, el cardenal Ascanio Sforza -hermano del duque de Milán- previniendo al papa de los peligros que entrañaba una alianza con Francia (11.VI.1493), ${ }^{46}$ donde su hermano Jeroni intentaba disuadir a Carlos VIII de sus pretensiones sobre Nápoles. ${ }^{47}$ El datario no sólo trasmitía al papa las promesas de apoyo a su parentela que le hacían llegar los reyes españoles, ${ }^{48}$ sino que medió en la alianza del papa con Ferrante de Nápoles, asegurando el doble matrimonio de sus hijos respectivos a cambio de que el rey lograra de Virginio Orsini la devolución de Cerveteri y Anguillara. ${ }^{49}$ Ello le obligó a mantener una correspondencia directa con Federico, hijo del monarca napolitano, poniéndole al corriente de los obstáculos que había que remover para ganarse la confianza del pontífice. ${ }^{50}$

41 La firma de Llopis como testigo de estos pactos matrimoniales y ciertos acuerdos sobre la dote en Parisi (ed.) 2015: 157-171.

42 Carta del datario Joan Llopis al almirante Enrique Enríquez, 28 marzo 1493; en Sanchís Sivera 1919: 19-20; véase también Chabàs 1893: 87 y 131; Oliver y Hurtado 1896: 437-439.

43 Torre 1962, IV: 141, 142, 148, 155, 196, 198 у 250.

44 Trinchera 1868, I: 258-259 y 363-364.

45 Burckardt 1907-1942, I: 447. Sobre esta embajada cfr. Fernández de Córdova Miralles 2005: 287-299.

46 Pellegrini 2002a, I: 433-434; II: 448. También AA.VV. 1936: 119.

47 Zurita 1996, I: 80-81.

48 Véase el despacho de Dionigi Pucci, embajador de Piero de Medici en Roma, 8-9 mayo 1493; Figliuolo 2015 (agradezco a Bruno Figliuolo la consulta de este trabajo antes de su publicación).

49 Despachos de Dionigi Pucci, embajador de Piero de Medici en Roma, 23 y 30 abril 1493; Figliuolo 2015.

50 Despachos Federico a Ferrante de Nápoles, 22 julio 1493, y el de Dionigi Pucci, 27 octubre 1493; Figliuolo 2015.
La gestión del datario fue tan eficaz que a finales de junio Isabel y Fernando le escribieron agradeciéndole «la diligencia e afección con que entendeys en la dirección de nuestros negocios en essa Corte», y rogándole que continuara así «ca será darnos causa para que hayamos encomendado vuestro bien y honra» (21.VII.1493)..$^{51}$ No era para menos. Aquel año se despacharon con su firma las "bulas alejandrinas" de América, y asistía como testigo a la concertación del doble enlace matrimonial que sellaba la alianza del Papado con la Casa Trastámara (11.VIII.1493). Ponderando el lugar «che tene apresso la predicta Santita», Ferrante de Nápoles le agradeció su apoyo en la resolución de sus diferencias con Alejandro VI, para llegar a un entendimiento mutuo antes de que Carlos VIII reivindicara el Regno. ${ }^{52}$ Como recompensa, ordenó a sus agentes que le facilitaran el capelo «perche la virtu suo cosi ricerca». ${ }^{53}$ En la trastienda de aquella negociación descurría el sordo enfrentamiento con Ascanio Sforza, que había vetado el ascenso de Llopis al cardenalato, por considerarle amigo de Ferrante de Nápoles y, por tanto, posible rival ante su elección al papado. ${ }^{54}$ Llopis tuvo que atender, de hecho, los requerimientos de algunos potentados italianos como el marqués de Mantua, que solicitaban el capelo para su segundo hijo Segismondo Gonzaga. ${ }^{55}$ Finalmente acabó ganando la batalla al Sforza pues, a fines de agosto, éste abandonó sus apartamentos en el Vaticano por temor a una represalia papal, dejando el camino expedito al datario y al cardenal de Monreal -Juan de Borja y Navarro- para gestionar la elección cardenalicia del 20.IX.1493. Aunque Llopis no obtuvo el capelo, ${ }^{56}$ Ferrante volvió a promocionar su candidatura dos meses después. ${ }^{57}$ Necesitaba su ayuda para defender el matrimonio de su hija Beatriz del divorcio planteado por su esposo Ladislao de Hungría, y para asegurar el entendimiento con el papa ante la rebeldía del cardenal Giuliano della Rovere. ${ }^{58}$

Como secretario del pontífice, intervino en los asuntos domésticos vinculados a su política internacional. Firmó las instrucciones dirigidas al duque de Gandía durante su viaje a la Península Ibérica para contraer matrimonio con María Enríquez y redondear sus estados. El duque quiso gratificarle solicitando al papa "gràcies i mercès, e el faça gran, car verdaderamente ses vertuts e bons servís l'hi mereixen» como "antic criat tan fel i bon servidor» (9.XI.1493); ${ }^{59}$ y por su parte, el obispo de Perugia le felicitó por las rentas recibidas en el reino de Nápoles, augurándole futuras ganancias en la Península Ibérica (18.IV.1494). En Valencia Jeroni se incorporó al grupo de consejeros del duque y fue el único que no vio cuestionada su credibilidad cuando fue escogido en septiembre de 1494 para viajar a Roma y exculpar al hijo del papa de ciertos desórdenes personales y financieros. Aunque Jeroni no pudo desplazarse, envió sus informes a través de su hermano (4.X.1494), ${ }^{60}$ que también intervino en la corres-pondencia de Alejandro VI con su hija Lucrecia (24.VII.1494), a quien

51 Carta de Fernando el Católico a Joan Llopis, 21 julio 1493; en Torre 1962, IV: 250.

52 Trinchera 1868, II: 143-144.

53 Ibídem, II: 143-144, 170-171 y 215-217.

54 Desjardins 1859, I: 488-489.

55 Bellonci. 1939: 73.

56 Trinchera 1868, II: 241-244.

57 Ibídem, II: 319-320.

58 Ibídem. II: 137-238, 292-293 y 348-356.

59 Batllori (ed.) 1998:60.

60 Ibídem: 74, 156-158 y 159-161. 
servía otra Lucrecia (o Joana) Llopis que algunos consideran sobrina ${ }^{61}$ y otros hija del datario. ${ }^{62}$ Ésta acompañó a la hija del papa durante su estancia en Pésaro, donde casó con el médico Gian Francesco Ardizi y, en enero de 1502, agasajó a su antigua señora a su paso por la ciudad camino de Ferrara. ${ }^{63}$ No fue la única mujer del entorno papal vigilada por el datario, pues Francesc Gasset también le informaba desde Capodimonte de la resistencia de Julia Farnese a volver a Roma por la oposición de su marido (19.X.1494), y del envío de un correo de Adriana del Milà por medio de Jeroni Llopis (5-7.XI.1494). ${ }^{64}$

El datario intervino en los acuerdos firmados por el papa y Alfonso II de Nápoles (22.III.1494) para frenar las pretensiones de Carlos VIII de Francia sobre el reino de Nápoles, ${ }^{65}$ actuó como testigo en el enlace de Jofré de Borja -hijo de Alejandro VI-con Sancha de Aragón, hija ilegítima de Alfonso de Aragón. ${ }^{66}$ Como es sabido, Isabel y Fernando promovieron aquella negociación asegurado al papa su auxilio militar, que Llopis tutelaba revisando la correspondencia de éstos con Alfonso de Nápoles. ${ }^{67}$ Además, el datario tenía hilo directo con Francesc Desprats, nuncio en la corte hispana, que en aquellas fechas le informaba del desafecto que mostraba hacia el papa el embajador Diego López de Haro recién llegado de Roma, y de cuestiones relacionades con el pago de correos o rentas eclesiásticas (5 y 10.X.1494). ${ }^{68}$

En la formación del frente pro-aragonés, Llopis afianzó la amistad de Piero de Medici de quien esperaba beneficios para sus familiares y tal vez su promoción al cardenalato «perchè la sua signoria -decía el embajador florentino- è molto avida del cappello rosso" (16.VI.1494). ${ }^{69}$ En este contexto, informaba al señor de Florencia de la política papal ante el descenso de Carlos VIII (16.II.1494), y le exhortaba a recibir al cardenal Alessandro Farnese como legado del Patrimonio con la promesa de gratificar a su hermano el cardenal Giovanni de Medici con beneficios en Toscana (20.VI.1494). ${ }^{70}$ Con todo, la ambigüedad florentina exasperó al datario que en diciembre reprochó bruscamente a Giovanni de Medici el intolerable retraso de la entrevista que el papa le llevaba proponiendo desde hacía meses: «Nostro Signore stava con admiratione et tante schuse no admetterebe» (6.XII.1494). ${ }^{71}$

Llopis siguió de cerca las operaciones militares contra la invasión francesa, manteniendo contacto epistolar con el gobernador de Spoleto -Joan de Borja-Llançol y de Moncada (20.VI.1494)-, con Joan de Vera (29.VIII.1494) destinado en Basanello probablemente para vigilar las operaciones en el reino de Nápoles, y con Bernardino López de Carvajal, envia-do a Anagni en julio de $1494 .{ }^{72}$ Asistió a la audiencia

61 Gregorovius 2008: 114.

62 Bellonci 1939: 77; Cruselles Gómez 1995: 246.

63 Bellonci 1939: 112 y 313.

64 Sendas cartas autógrafas en ASV, Archivum Arcis, Arm. I-XVIII, 5023, fol. 95rv; 5025, fol. 78rv, (agradezco a María Toldrà la noticia y transcripción de ambos documentos que Miguel Batllori localizó y pensaba incluir en el Epistolari Borja).

65 Pellegrini 2002a, II: 487.

66 Véase la serie de documentos en Parisi (ed.) 2015: 42 y 198-213.

67 Despacho de Bartolomeo Ugolini y Francesco Cappello a Piero de' Medici, Carsoli, 10 agosto 1494; Figliuolo 2015.

68 ASV, Archivum Arcis, Arm. I-XVIII, 5023, fol. 21rv y 65 rv.

69 Desjardins 1859, I: 488-489; Picotti 1927: 493-494 y 706-710.

70 Figliuolo 2015.

71 Picotti 1927: 494-495.

72 Batllori (ed.) 1998: 107-108. La carta de Joan de Vera al datario solicitando dinero se halla en ASV, Archivum Arcis, Arm. I-XVIII, 5022, fol. 68r-V. que Alejandro VI ofreció al príncipe de Anhalt (24.XI.1494) para requerir la ayuda del rey de Romanos, negoció con el embajador castellano Garcilaso de la Vega la reconciliación con el duque de Milán, y recibió con el cardenal Carvajal a las tropas francesas en diciembre de $1494 .^{73}$ La descomposición del colegio cardenalicio permitió a Llopis erigirse -con el otro secretario Bartolomeo Flores- en verdadero protagonista de los asuntos de Estado. ${ }^{74}$ No es casualidad que por aquellas fechas se multiplicaran los ofrecimientos de beneficios por parte de las dos potencias enfrentadas: Carlos VIII le otorgó la reserva del obispado de Carcassone (23.III.1495) que administraría tres años después (23.XII.1497), ${ }^{75}$ y los reyes españoles dos prebendas en Salamanca y Astorga (22. II.1495), una reserva del deanato de Cartagena (23.III.1495) y la de un beneficio en Mallorca (7.X.1495) ${ }^{76}$ probablemente la sacristía que costó a Llopis 700 ducados entregados al papa para pagar el rescate de Giulia Farnese, secuestrada por los franceses. ${ }^{77}$ Durante estas agitadas jornadas, Llopis siguió al papa como la sombra al cuerpo. En junio de 1495 le acompañó en su viaje a Orvieto para evitar encontrarse con el rey francés que regresaba de Nápoles; ${ }^{78}$ y poco después se adelantó a Perugia para preparar su alojamiento, pudiendo visitar a la beata Colomba de Rieti -mística terciaria dominica famosa por sus visiones proféticas- a la que sometió a un riguroso interrogatorio con otros cardenales. ${ }^{79}$

En su diócesis de Perugia, impulsó algunos proyectos literarios y artísticos. Michele Ferno, discípulo de Pomponio Leto, le dedicó entonces su Braccii Perusini vita et gesta contenida en la costosa edición de las obras de Giannantonio Campano (Campani Opera omnia, Romae, Eucharium Silber, 1495). ${ }^{80}$ La obra relata la vida del célebre condotiero Braccio Fortebracci da Montone, implicado en diversas campañas militares en el Lazio y el reino de Nápoles. En su epístola introductoria se refiere al ingenium unicum y a la sanctissima vita del obispo, tan ajeno de toda agresividad y efusión de sangre, como pronto a defender con interés patrio (patrio studio) los derechos de la dinastía aragonesa (nationis tuae) de Nápoles adversus Gallorum tempestatem. Ferno pondera el valor de Fernando II de Nápoles, sucesor de Alfonso II tras su abdicación, y capaz de empeñar su vida y su imperio para defender sus derechos al trono, cuya legitimidad había sostenido el propio Michele Ferno en su Epitome de Regno Apuliae et Siciliae. ${ }^{81}$

Al interés por el pasado de su diócesis y la propaganda pro-aragonesa, hay que añadir las empresas artísticas en su elegante residencia fortificada de Pieve del Vescovo, cerca de Corciano en Umbria (Fig. 1). Testimonio de ello son los grandes escudos, con el lobo pasante hacia la izquierda, que figuran en uno de los lados del basamento del castillo (Figs.

\footnotetext{
73 Zurita 1996, I: 149; Woodward 2005: 90-91.

74 Pellegrini 2002a, II: 582.

75 AA.VV. 1936: 119.

76 Pons Alós y Cárcel Ortí 2005: 938.

77 Sobre Giulia Farnese y otros asuntos personales tratan tres cartas de Francesc Gasset al datario consultadas por Bellonci 1939: 639-641. Véase también el relato de Domingo de Zaragoza, Historia del pontificado de Alejandro VI hasta 1501, cap. 305; en Biblioteca del Seminario Diocesano (Gerona), ms. 12 [Agradezco a Maria Toldrà la consulta de esta crónica cuya edición está preparando].

78 Fumi 1877: 11 y ss.

79 Baglioni 1845: 846; Casagrande y Monacchia 2001, III: 937-939.

80 Campanus 1929: XXVIII.

81 Ceresa 1996.
} 
FIGURA 1

Residencia fortificada de Pieve del Vescovo (Corciano), construido a fines del siglo xIV sobre una construcción preexistente. Fotografía: http://www.beniculturali.it

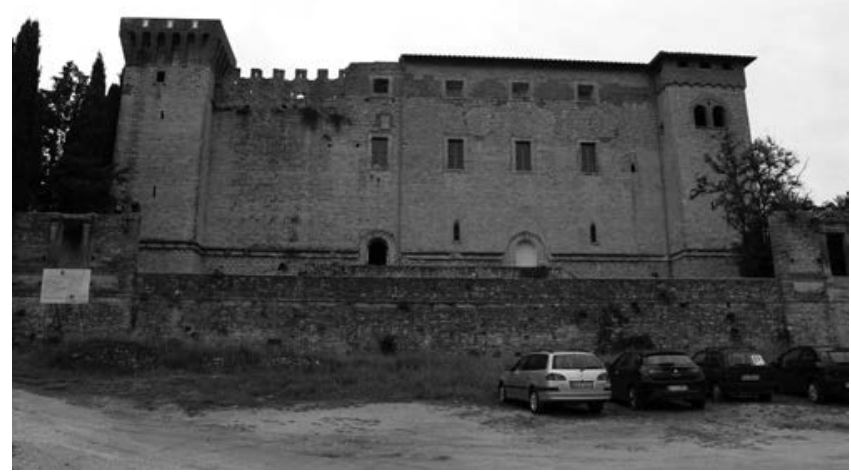

FIGURA 2

Escudo cardenalicio de Joan Llopis (lobo pasante hacia la izquierda). Basamento del castillo de Pieve del Vescovo

(Corciano). Fotografía: www.medioevoinumbria.it

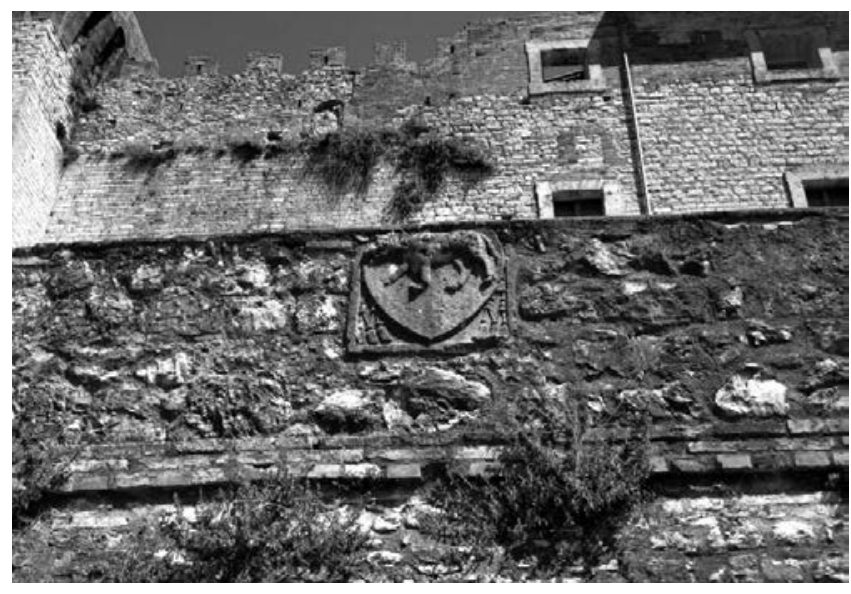

FIGURA 3

Escudo cardenalicio de Joan Llopis. Castillo de Pieve del Vescovo (Corciano). Fotografía: ww.beniculturali.it

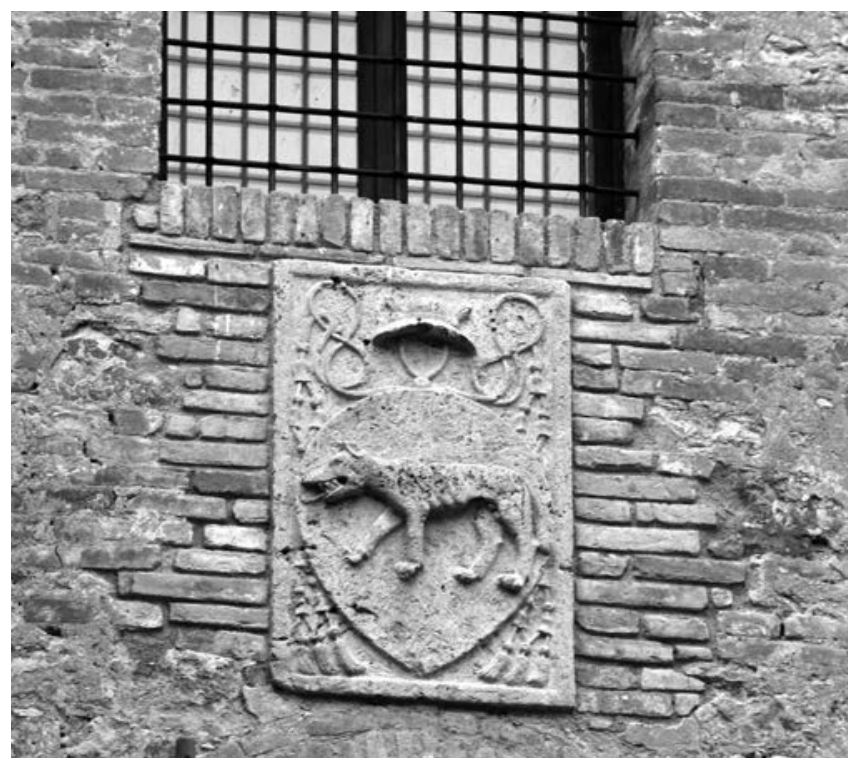

FIGURA 4

Sacra conversación entre los santos Juanes Bautista y Evangelista; Trinidad. Pintoricchio (taller). 1496. Fresco de la capilla privada del Castillo de Pieve del Vescovo. Actualmente en la sacristía de la Iglesia de San Giovanni

Battista. Fotografía: Abbozzo, y Tiroli (dir.). 2004

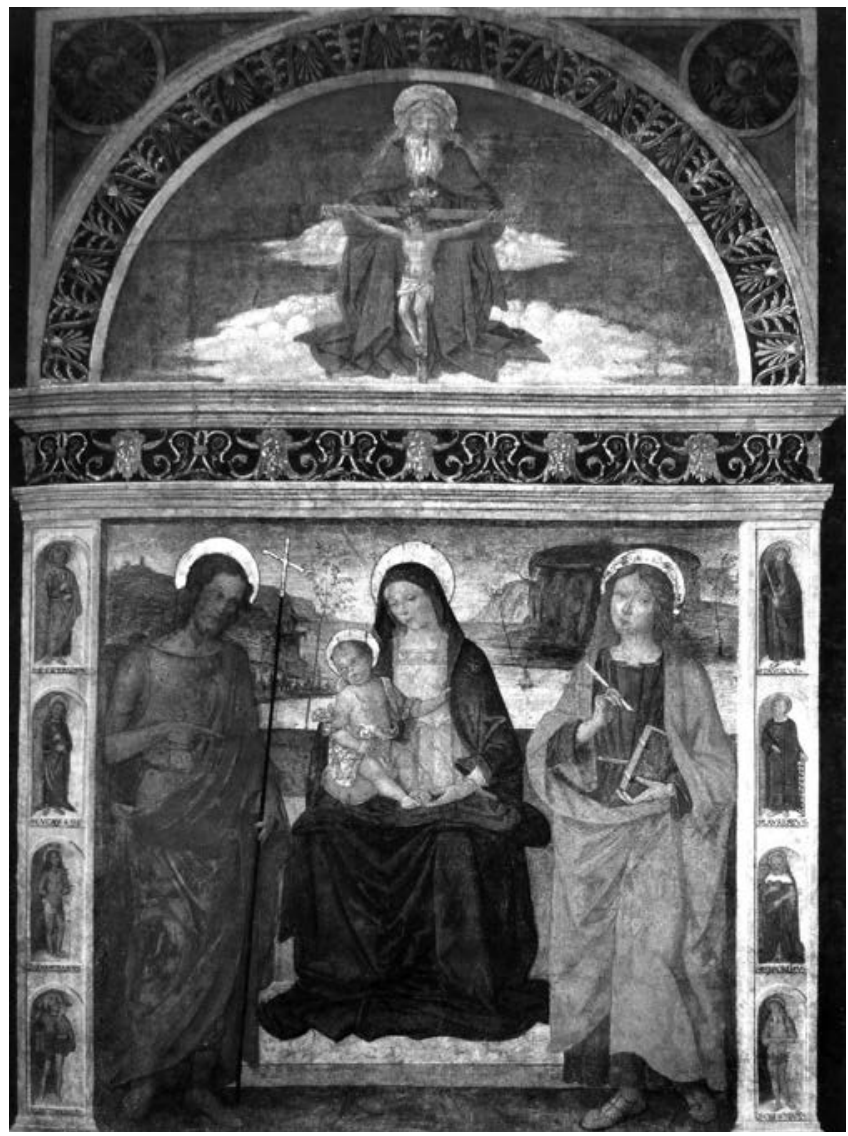

2 y 3). ${ }^{82}$ Se trata del mismo animal heráldico que figura en su sello ovalado sin leyenda conservado en el archivo de la catedral de Valencia (18.IV.1494). ${ }^{83}$ Otros dos lobos alusivos al cardenal han aparecido en la reciente restauración del fresco de notables dimensiones que hizo pintar en su capilla privada del palacio (hoy en la sacristía de la Iglesia de San Giovanni Battista) para celebrar quizá su elección cardenalicia en febrero de $1496 .^{84}$ Se trata de la Sacra conversación entre los santos Juanes Bautista y Evangelista (Fig. 4) atribuido al taller de Pinturichio, que acababa de culminar los frescos de los Apartamentos vaticanos para Alejandro VI. En él se representa a la Virgen María con el Niño en brazos entre los dos santos Juanes que llevan su nombre..$^{85}$

82 Mancini 2003: 14-15 y 38-40. Seguramente por error, se le ha asignado un toro blanco en campo rojo-verde apelando a sus vínculos con los Borja: Bigazzini, G., Vescovi dell'illustrissima città di Perugia, copia de Pompeo Balzi (1642), Biblioteca Comunale Augusta di Perugia, ms. 1336, c. 9v. Otra extraña reproducción de su escudo con un toro tendido en Chacón 1677: 186.

83 El sello se describe como un camafeo con un cuadrúpedo hacia la izquierda inscrito en él, sin leyenda; Torre y del Cerro 1921: 91.

84 Véase la propuesta de Isabella Farinelli en Mancini 2003: 38-39; Abbozzo y Tiroli (dir.) 2004: 66-67 y 170.

85 Galli 2001. 
Los otros santos representados en los nichos que enmarcan la escena tienen también su significado: ${ }^{86}$ en la parte más alta los dos príncipes de la Iglesia, Pedro y Pablo, expresan la difusión del mensaje evangélico a los judíos y a los gentiles desde las altas esferas del mundo romano. En el segundo orden aparece San Lucas, imago brevis de los evangelistas representando la palabra, y San Lorenzo, imagen de la iglesia perugina. En la tercera fila figura San Sebastián, protector de las calamidades y particularmente oportuno en aquellos turbulentos años, y San Jerónimo -emblema de la doctrina y la teología- con las vestes cardenalicias alusivas al título que acababa de obtener el datario. Finalmente, en la base aparecen San Onofrio, venerado en la catedral de Perugia, y San Cristóbal, ligado al culto eucarístico como portador de Cristo viviente. La atmósfera serena de la Sacra conversazione no podía contrastar más con la calata de Carlos VIII y probablemente haya que relacionar con el temperamento pacífico que Michele Ferno atribuía al prelado valenciano por aquellas mismas fechas.

Finalmente también se ha atribuido al cardenal la Pala di San Francesco del hospital de Corciano, donde figuran dos cabezas de lobo con las fauces abiertas, ${ }^{87}$ y el gran fresco del presbiterio de la capilla de San Giovanni, en el palacio perugino, representando a la Virgen entronizada con el Niño en brazos y a sus lados Santa Isabel, San José y un San Juan Bautista niño que extiende a Jesús la enseña de la cruz.

\section{LOS PLIEGUES DE LA PÚRPURA (1496-1497)}

El 19 de febrero de 1496, Alejandro VI decidió elevarlo al cardenalato con el título de Santa María in Transtevere en la única promoción donde todos los neopurpurados eran parientes o familiares. ${ }^{88}$ Cuatro días después informó a Isabel y Fernando consciente de que recibirían la noticia "magna gratulatione et cum iucunditate".$^{89}$ Como ha mostrado Marco Pellegrini, esta promoción se enmarca en el proceso de faccionalismo y politización del colegio cardenalicio que se intensificó durante el pontificado de Alejandro VI a raíz de la tensión internacional y las promociones estratégicas realizadas por el papa para garantizar lealtades y reforzar su discutida posición en una Curia dividida. ${ }^{90} \mathrm{~A}$ diferencia de otros pontífices como Sixto IV, que optó por promover a sus propios familiares, el segundo papa Borja incorporó al colegio cardenalicio a valencianos y catalanes de modesta extracción social y una fidelidad acrisolada por años de servicio en su familia desde sus tiempos de cardenal. Opción que llevó aparejada una serie de irregularidades y anomalías para dotar de una base económica a los nuevos purpurados carentes del suficiente arraigo en las estructuras sociales italianas o del sostenimiento de los príncipes seculares.

Aunque la púrpura le obligó a ceder sus oficios de datario y secretario, Llopis siguió acumulando beneficios y dignidades: en 1496 recibió una prebenda y el oficio de tesorero en Burgos, una iglesia parroquial en Salamanca y el priorato

\footnotetext{
86 Tiroli 2004: 67 .

87 Ibídem: 63.

${ }^{88}$ Fue elegido el 19 febrero y recibió el capelo el día 24; AA.VV.

89 Suárez Fernández 1971, IV: 495-496.

90 Pellegrini 2002b: 18-20.
} 1936: 119 secular de la iglesia colegial de San Miguel de Volterra;91 en 1497 obtuvo el obispado de Oloron (17.IV.1497), que resignó al cabo de un año reservándose una pensión de 400 florines (28.V.1498); la abadía de San Leonardo di Siponto (Manfredonia) perteneciente a la orden teutónica, que retuvo hasta su muerte frente a las tentativas del gran maestre de hacerse con ella; y una renta de 300 florines sobre los frutos del monasterio de San Gerberto de Aurillac; finalmente en 1498 recibió la encomienda del monasterio de San Pedro de Viena que acabó resignando (13.XI.1500), y la de la abadía cisterciense de Santa Maria de Corazzo (30.VI.1498) que cedió a los pocos meses a Bartomeu Marti (14.XII.1498).92

En una carta de 1496, el nuevo cardenal quiso aclarar a Isabel y Fernando ciertos pleitos beneficiales: les aseguró que había renunciado a un arcedianato sevillano antes de conocer la oposición de los reyes, pero retenía la abadía de San Pelayo con el apoyo del papa sin lograr hacer valer sus derechos por la resistencia de los religiosos y los oficiales reales. ${ }^{93}$ Para ganarse a los monarcas, les prometió que si le reconocían la posesión, facilitaría el paso del cenobio a la Observancia con el envío de ocho o diez religiosos de Poblet, emplearía sus rentas en reparar lo destruido por los rebeldes, e impulsaría que «todos los monesterios de sus Reynos sean reduçidos a la observançia por serviçio de Dios y conservaçión de la santa religión». Llopis denunciaba, sin embargo, ciertos problemas de comunicación, pues ni él había recibido toda la correspondencia que los monarcas aseguraban haberle escrito, ni ellos contestaban a las cuestiones que les planteaba en sus misivas. Finalmente les reiteró su colaboración en la obtención de la décima y cruzada, justificando la resistencia del papa a ciertas exigencias de los reyes por no haber aceptado gestionar aquellas concesiones como el datario les indicó durante la embajada del conde de Tendilla (1486-1487).

Durante este tiempo no se despegó del pontífice. Intervino en el traslado secreto del duque de Gandía desde la península Ibérica a la Ciudad Eterna para hacerse cargo de las tropas pontificias. Genís Fira, secretario del duque, le escribió desde Génova para informar de los gastos del viaje gestionados por su hermano Jeroni y Jaume Serra (27.IV.1496), ${ }^{94}$ y obtener las galeras necesarias para desplazarse a Roma con la ayuda del gobernador de Génova y del embajador de los Reyes Católicos en la ciudad ligur. Cuatro meses después, el cardenal acompañó al duque en su solemne entrada en la Urbe (6.VIII.1496), ${ }^{95}$ como había hecho dos meses antes con los príncipes de Esquilache, Jofré de Borja y Sancha de Aragón (20.V.1496). ${ }^{96}$

Llopis tuvo en aquellos días una intensa actividad litúrgica. El 11 de agosto celebró la solemne Misa por el aniversario de la elección de Alejandro VI, y el 26 de octubre bendijo las tres banderas que recibió el duque de Gandía como nuevo gonfaloniero de la Iglesia que se aprestaba a emprender la campaña contra los Orsini, frustrada en la humillante

91 Pons Alós y Cárcel Ortí 2005: 938.

92 Russo 1977: 86 y ss.

93 Carta de Joan Llopis a los reyes Isabel y Fernando (Roma, c. 1496), en Archivo de los Condes de Cedillo (Madrid), Caja 41, doc. 42.

${ }_{94}$ Carta de Genís Fira al cardenal desde Génova (27.IV.1496) en Archivio di Stato di Firenze, Signori, Dieci di Balia, Otto di pratica, Legazioni e commisarie, misive e responsive, n. 66, fol. 87rv.

95 Domingo de Zaragoza: cap. 219.

96 Ibídem: cap. 192. 
derrota de Soriano (25.I.1497). ${ }^{97}$ Mientras Jeroni participaba en esta acción militar, su hermano acompañó al papa durante su breve estancia en Ostia en los meses de marzoabril, tras la toma de la fortaleza por las tropas españoles del Gran Capitán. ${ }^{98}$ Aquel año el maestro de ceremonias registra su participación en la Misa de la Anunciación en la basílica de Santa Maria sopra Minerva ante el papa (28.III.1497), en la procesión del Corpus Christi en que publicó las indulgencias, y en la primera Misa nocturna del día de Navidad. ${ }^{99}$

Llopis no abandonó sus relaciones con una Florencia conmocionada por la exaltada predicación del dominico Girolamo Savonarola y la rebelión de Pisa. ${ }^{100}$ En enero de 1496 el gobierno de la república acudió a él y a Bartomeu Martí en defensa del fraile para que pudiera predicar durante la Cuaresma. ${ }^{101}$ Llopis contemporizó con las autoridades florentinas y desaprobó la excomunión de Savonarola (12.V.1497), a quien intentó trasladar a Roma para lograr una reconciliación. Durante este tiempo Nicolás Maquiavelo recurrió a su ayuda para defender el patronato de la parroquia de Fagna reivindicado por su familia frente a los Pazzi (2.XII.1497). ${ }^{102}$ La influencia del cardenal también se extendía a los episcopados ingleses. En junio de 1497 escribió a Enrique VII de Inglaterra para negociar el nombramiento de las sedes de Durham vacante desde 1494-y Worcester, que Llopis pretendía entregar a su familiar Gaspar Golfo, desplazado a Inglaterra para negociar el asunto con el monarca. ${ }^{103}$ Tres años más tarde el cardenal volvería a intervenir solicitando la sede irlandesa de Glendalough para el candidato propuesto por Enrique VII. ${ }^{104}$

Desde su encumbrada posición facilitó el ascenso de familiares o parientes todavía no bien identificados, como aquel Joan Llopis -protonotario apostólico lugarteniente de César Borja en el gobierno de Orvieto (1496-1497)-, ${ }^{105}$ Miquel Llopis -caballero del Hospital de San Juan de Jerusalén que recibió un beneficio en la diócesis de Teano (4.VIII.1497)-, o la citada dama de compañía de Lucrecia Borja. Entre sus protegidos se encontraba su antiguo preceptor Francesc Gasset -que llegó a ser scriptor de cartas apostólicas, maestro del sacro palacio y efímero sucesor suyo en el obispado de Perugia-, Joan Castellar -que desempeñó algunas misiones en Perugia y Nápoles, y en 1503 heredó su título cardenalicio-, su secretario Adriano Caprini da Viterbo y otros miembros de su casa como el protonotario Troilo Baglioni, su camarero Juan Carmona, o su familiar Tito de Sutrio que pronuncio su oración fúnebre.

Los Reyes Católicos continuaron solicitando sus servicios, agradeciéndole en agosto de 1497 «la liberalidat de que usó (...) con el inquisidor de Valencia sobre la canongia

97 El papa se dirige a él el 23 de marzo de 1497 para negociar una concordia con los Orsini tras la derrota de Soriano; cfr. Borràs i Feliu 1984: 25 y 27.

98 Burckardt 1907-1942, II: 19.

99 Ibídem.

100 Ridolfi 1981 (reed. 1997): 128, 161, 165 y 190; Cordero 1988.

101 Marchese 1850. Sobre Bartomeu Martí cfr. Fernández de Córdova Miralles 2012, 32: 730-732.

102 Machiavelli 1995: 457-458.

103 Gairdner 1861, I: 102-103; Wilkie 1974: 55-57.

104 Ibídem: 68.

105 El homónimo recibe pagos como lugarteniente del gobierno de la ciudad entre diciembre de 1496 y julio de 1497; Menotti 1917, II: $100,165,168$ y 306. de Burgos» (20.VIII.1497), ${ }^{106}$ y su "buena voluntad" en la obtención de ciertas bulas para el monasterio de Jerusalén de Zaragoza (15.VI.1498). En otras ocasiones le encomendaron los asuntos de micer Franch o del secretario Juan de Coloma; le pedían que no molestase a Alonso de Mur en la posesión de una canonjía de Gerona (7.VIII.1498); o que recibiera como familiar a Antón Sánchez, prior de Sariñena y agente del tesorero Gabriel Sánchez (10.X.1498). ${ }^{107}$ Su afinidad con los Reyes Católicos explica que celebrara la Misa por la muerte de su primogénito, el príncipe Juan, en la abarrotada iglesia de Santiago de los Españoles (16.I.1498), ${ }^{108}$ y que vigilara las obras del monasterio de San Pietro in Montorio auspiciadas por los Reyes Católicos (17.VIII.1498) como exvoto por su heredero. ${ }^{109}$

De otro lado el embajador Garcilaso de la Vega recurría a él para conocer el parecer del papa o resolver complejas negociaciones eclesiásticas (cuestiones jurisdiccionales, asuntos inquisitoriales, etc.) que agradeció solicitando a los reyes en su favor «algun obispado pequeño, tal como Badajoz, o Ciudad Rodrigo", que enmendara el intento papal de otorgarle la sede de Segovia tras el fallecimiento de Juan Arias Dávila (21.IV.1498). ${ }^{110}$

PRIVADO DEL PAPA: VIRAJES DIPLOMÁTICOS Y MECENAZGO ROMANO (1497-1501)

Gracias a su fidelidad y discreción, Llopis llegó a convertirse en el "gran privado del papa", permaneciendo a su lado durante los virajes políticos que emprendió en la segunda parte de su pontificado. ${ }^{111}$ A principios de 1497, colaboró en el nuevo acercamiento de Alejandro VI a Federico de Nápoles a cambio de ciertos territorios para el duque de Gandía que gestionó Jeroni como delegado papal. ${ }^{112}$ Tras el fallecimiento del duque (14.VI.1497), César acudió al cardenal para sondear la opinión del papa sobre su renuncia al capelo cardenalicio para sustituir a su hermano en el ducado, ${ }^{113}$ y un año después testificó en el proceso de secularización y el traspaso de ciertos bienes del difunto duque a César, quien le pagó con algunos de sus antiguos beneficios: una prepositura en la iglesia de Valencia, una canonjía en la iglesia de Tudela (3.VIII.1498), la rectoría de la Colegiata de Gandía (26. IX.1498) y la encomienda del monasterio de Ripalta y de San Leonardo en el reino de Nápoles (20.X.1498). ${ }^{114}$ Alejandro VI le confió la custodia de su hija Lucrecia en los meses pre-

106 Carta de Fernando el Católico al obispo de Cartagena, 20 agosto 1497; en Torre 1965, V: 535-536.

107 Torre 1966, VI: ad indicem.

108 Sobre esta celebración romana cfr. Fernández de Córdova Miralles, Á. y Calvo Fernández, V. La muerte del heredero. Liturgia y humanismo por el príncipe Juan en su marco europeo (en preparación).

109 Torre 1966, VI: 117. La empresa arquitectónica ha sido estudiada por Cantatore 2007.

110 Garcilaso de la Vega (ed.) 1842: 10-11.

111 Zurita 1996, I, libro II, cap. XL: 325.

112 Borràs i Feliu 1984: 27.

113 Pellegrini 2002a, II: 653-655. Sobre la secularización de César cfr. Pellegrini 2005; Fernández de Córdova Miralles 2009.

114 Cfr. Sanudo 1879-1903, I: 1110; II: 67 y 269. Sobre los beneficios napolitanos véase la carta de Alejandro VI a Federico de Nápoles, 20 octubre 1498; en Borràs i Feliu 1984: 307-308. La intervención de Llopis en la devolución de los bienes muebles valencianos (19.XII.1498) en Parisi (ed.) 2014: 249-253. 
vios a su matrimonio con Alfonso de Aragón -hijo ilegítimo de Alfonso II de Nápoles- del que participó como testigo (21. VIII.1498). ${ }^{115}$ En el banquete nupcial sirvió como maestresala junto con el cardenal de Monreal, y en los festejos posteriores recibió de César la divisa de un oso con unos versos alusivos a la incómoda presencia de los Orsini en las tierras de la Iglesia («Ursinos foeros peperit patientia longe / temporis ut arbos lumine resurgam?»), lo que suponía una invitación a apoyar la campaña que preparaba contra esta familia del Lazio. ${ }^{116}$

El papa contó con sus servicios en su alianza con Francia, planteando su envío a la corte de Luis XII en compañía de César. ${ }^{117}$ Esta maniobra tan peligrosa para la política española, enfrentó al cardenal con su antiguos aliados, de manera que el agente enviado a Roma para hacer recapacitar al papa -fray Bernat Boïl-sólo logró «reñir con el cardenal de Perusa» (VIII.1498). ${ }^{118}$ Para llegar a un acuerdo, Llopis recurrió al arzobispo Jiménez de Cisneros prometiendo resolver sus asuntos en la Curia si facilitaba el traspaso de los beneficios de César en su persona y en la del cardenal Joan de Borja-Llançol de Romaní y Moncada, sobrino del papa (3.IX.1498). ${ }^{119}$ Alejandro $\mathrm{VI}$ estaba decidido a encumbrar a su antiguo datario $\mathrm{y}$, si no pudo enviarle a Francia por los recelos de Luis XII, al menos le otorgó el arzobispado de Capua (15.X.1498) -con una renta anual de 6.000 ducados- tras ceder la sede de Perugia a Francesc Gasset, y en el reino de Nápoles la encomienda del monasterio cisterciense de Ripalta y la de Santa Maria de los Teutónicos que habían pertenecido a César (20.X.1498). Su firma como testigo muestra que también siguió de cerca la ventilación de los bienes del fallecido duque de Gandía, estimados en 30.000 ducados (19.XII.1498). ${ }^{120}$

El momento de mayor tensión se alcanzó en la crisis diplomática suscitada en diciembre de 1498 entre los embajadores de los Reyes Católicos y el papa, recluido en un gobierno personalista al que sólo tenían acceso Llopis y Joan de BorjaLlançol. ${ }^{121}$ Ambos asistieron a las tensas conversaciones de enero de 1499 e intervinieron en las maniobras posteriores para llegar a una reconciliación. ${ }^{122}$ Los dos participaban además en las diversiones pontificias, como la gran partida de caza organizada a fines de enero sobre Ostia y sus alrededores boscosos. ${ }^{123}$ Como intérprete y portavoz del papa, Llopis comunicó a los embajadores que su Santidad alababa la política reformadora de los monarcas pero no estaba dispuesto a perder las rentas de los monasterios reformados (3.VI.1499), ni acceder a sus requerimientos de restituir Benevento a la

115 Gregorovius 2008: 137-139; Bellonci 1939: 161; Parisi (ed.) 2014: 228-230.

116 Uhagón y Guardamino (ed.) 1916: 82-93; Domingo de Zaragoza: cap. 290.

117 Zurita 1996, II: 112. Sobre esta temática cfr. Fernández de Córdova Miralles 2007a.

118 Núñez 1916: 440.

119 Archivo Histórico Nacional (Madrid), Universidades, Leg. 757, fol. $145 r$

120 Parisi 2006-2007: 224-225, 227, 235-236 y 247.

121 En junio de 1499, el embajador Girolamo Donato escribía a la Señoría que «niun poteva col Papa, ma solo lui feva quello li pareva, licet do siano li primi apresso soa Santità, videlicet, il cardinal Capua, olim suo datario, et il nipote cardinal Borgia, et non ha consultori»; Sanudo 1879-1903, II: 1011; Zurita 1996, II: 135 y 145; Woodward 2005: 144-145.

122 Fernández de Córdova Miralles 2005: 394-406; AA.VV. 1936: 119.

123 Bellonci 1939: 169.
Iglesia, alejar a sus hijos de Roma o reemprender la reforma, si no le entregaban las sedes abandonadas por César (Elna, Valencia y Coria). ${ }^{124}$ Mientras tanto Alejandro VI obtuvo el respaldo del rey francés en su proyecto de restauración de los Estados papales y dio su visto bueno al divorcio -estudiado por una comisión de la que formaba parte nuestro cardenalde Ladislao de Hungría y Beatriz de Aragón que rompía los lazos con la Casa de Aragón y facilitaba los proyectos de Luis XII de casar a un princesa francesa con el rey húngaro. ${ }^{125}$

En aquellos meses de zozobra internacional, Llopis informó a los agentes milaneses de que los tratos con Francia no se dirigían contra el duque Ludovico Sforza. ${ }^{126} \mathrm{Sin}$ embargo, en el consistorio del 7 de junio, sostuvo con otros purpurados la decisión pontificia de permitir la entrada de las tropas francesas en Génova, ${ }^{127}$ y a fines de julio culpabilizó al duque de Milán de haber facilitado el ataque otomano contra las posesiones venecianas y haber interceptado a un mensajero pontificio enviado a Francia. ${ }^{128} \mathrm{El}$ cardenal de Capua advirtió entonces al representante milanés que cuanto más se estrechara la amenaza turca más se justificaría la ocupación del ducado de Milán por el rey de Francia. Ante la crispación internacional el papa intentó mejorar sus relaciones con los Orsini, entablando el matrimonio de Jerònima de Borja-Llançol -hermana del cardenal Joan de Borja-Llançol y de Moncada- y Fabio, hijo de Paolo Orsini -hermano del cardenal Giambattista-; y con el linaje della Rovere mediante el matrimonio de Àngela Borja i de Montcada, sobrina del papa y hermana del legado papal Joan de Borja-Llançol, con Francesco Maria della Rovere, hijo del prefecto y heredero del ducado de Urbino. En los documentos generados por estos enlances encontramos estampada la firma del cardenal. ${ }^{129}$

La búsqueda de un entendimiento con los Reyes Católicos también benefició al antiguo datario, que obtuvo la posesión de Coria como administrador apostólico (15.X.1499), y probablemente el monasterio cisterciense de Valldigna (Valencia). ${ }^{130} \mathrm{~A}$ éstas concesiones debe añadirse el obispado de Collo con una renta anual de 6.000 ducados (7.IX.1499), la encomienda de la abadía nullius San Cristóbal de Castel Durante (Urbania) (1.IV.1500), y el monasterio benedictino de San Simpliciano en Milán. ${ }^{131}$ Tal acumulación de beneficios debió ganarle el apelativo de «cabeça principal e inventor de la simonía» que le adjudica el cronista aragonés Domingo de Zaragoza. ${ }^{132}$ Se trataba de una práctica difusa y difundida que los Reyes Católicos reprocharon al papa en aquel año de 1499 en que Llopis recuperó la sede de Perugia por fallecimiento de Francesc Gasset (29.VII.1499), a quien se la había cedido el año anterior por 7.000 ducados entregados al papa. De creer a Domingo de Zaragoza, Gasset lamentó aquel enjuague al confesar poco antes de morir «cómo

124 Despachos de Cesare Guasco, embajador milanés en Roma, a Ludovico el Moro, 3 junio y 14 julio 1499; en D’Auton 1891, I: 334-336 y 229-347.

125 De Berzeviczy 1911-1912: 233.

126 D’Auton 1891, I: 324-325; Pellegrini 2002a, II: 732.

127 Domingo de Zaragoza: cap. 302.

128 Pelissier 1898: 115, 117 y 124.

129 Parisi (ed.) 2014: 43, 244-247 y 259-263.

130 Ortí y Belmonte 1958; Martín Martín 1989: 286.

131 AA.VV. 1936: 119. El obispado de Collo podría tratarse de la sede húngara de Kalocsa-Bács o la Rodas (Collosensis).

132 Domingo de Zaragoza: cap. 229. 
lo matava l'obispado de Perosa, por haverlo comprado». Según el citado cronista, aquello no debió impresionar a un cardenal que también era "turpíssimo en toda sodomía", lo que no puede contrastar más con la sanctissima vita que le atribuía Michele Ferno. ${ }^{133}$

Tras la marcha de Joan de Borja Llançol como legado al Norte de Italia, Llopis se convirtió en «el primero junto al papa» (7.IX.1499), compartiendo con él momentos especialmente peligrosos. En enero de 1500, salvó a Alejandro VI del intento de los legados de Forlì de envenenarle. Cinco meses después, el 28 de junio de 1500, fue una barra de hierro la que estuvo a punto de acabar con su vida al caer una torre de la basílica vaticana "e dio en medio de su sanctedat e del cardinal, e non tochó ne fizo mal a ninguno d'ellos». ${ }^{134}$ Probablemente se trataba del gran candelabro de más de cien libras de peso que -según Jean d'Auton- desgarró las vestiduras del papa sin herirle. ${ }^{135}$ Sin embargo, el accidente más grave sucedió durante la tormenta del día siguiente, al desplomarse la techumbre de los apartamentos donde se encontraban. ${ }^{136}$ Llopis había ido a cerrar una de las ventanas de la sala cuando se derrumbó el dosel sobre el pontífice. Temiendo lo peor el cardenal salió pidiendo socorro ante la muerte del papa, cuando en realidad sólo recibió algunos rasguños de los que se recuperó pronto. Al año siguiente fue Llopis quien quedó malherido en un hombro durante una cacería cuando un gamo se abalanzó sobre el papa derribándole antes a él.

Estos accidentes no impidieron a nuestro protagonista emprender nuevos proyectos artísticos en el marco de las reformas urbanísticas acometidas con motivo del jubileo de 1500. Imitando el ejemplo pontificio, que acababa de embellecer la fuente de la basílica de San Pedro, encomendó al sottoarchitettore Donato Bramante la restauración de la fuente situada junto a su basílica del Trastévere, una de las más antiguas de Roma que recibía la misma conducción de agua que alimentaba la de San Pedro (Figs. 5 y 6). ${ }^{137}$ Llopis hizo trasladar la fuente al centro de la plaza, retiró la bandeja superior y decoró la inferior con cuatro cabezas de lobo broncíneas alusivas a su escudo (Fig. 7). Finalmente colocó una inscripción que conmemoraba su esfuerzo (Alexandri VI pont. max. felici auspicio) por restituir a la antigua belleza la fuente que existía vestustate informen (deteriorada por la incuria de los tiempos) ad commoditatem Populi Romani. ${ }^{138}$ El texto venía acompañado por unos elegantes dísticos latinos que comparaban la maternidad de la loba que amamantó a Rómulo con la paternidad del prelado-lobo que

133 Ibídem: cap. 305.

134 Ibídem: cap. 339.

135 D’Auton 1891, I: 295-296.

136 Véanse los relatos sustancialmente coincidentes de Zurita 1996, II: 209-210; Domingo de Zaragoza: cap. 339; Pastor 1942, III: 436 43. El despacho del embajador florentino Francesco Capello recogido en apéndice por Thuasne en su edición de Burckard 1883, III: 433-444.

137 Esta sintonía artística no pasó desapercibida a Vasari cuando escribe: «Servì Bramante ne' suoi principii per sotto architettore di papa Alessandro VI alla fonte di Trastevere, e parimenti a quella che si fece in su la piazza di San Pietro"; citado por Bruschi 1987: 122-124 y 344; Pocino 2002: 340-341; Company 2002: 226-228. D'Onofrio (1962: 14-15) data la restauración entre 1496 y 1501; en cambio Marías (1987: 24-25) es más restrictivo al fecharla en 1499 con motivo de la preparación del jubileo iniciada en noviembre de 1498.

138 Vincioli 1730: 110-111; Forcella 1879: 104-107. La inscripción también se recoge en Chacón 1677: 186.

\section{FIGURA 5}

Fuente de la Piazza Santa Maria in Trastevere (Roma). Restaurada por el cardenal Joan Llopis en fechas próximas al jubileo de 1500. Grabado siglo XIX

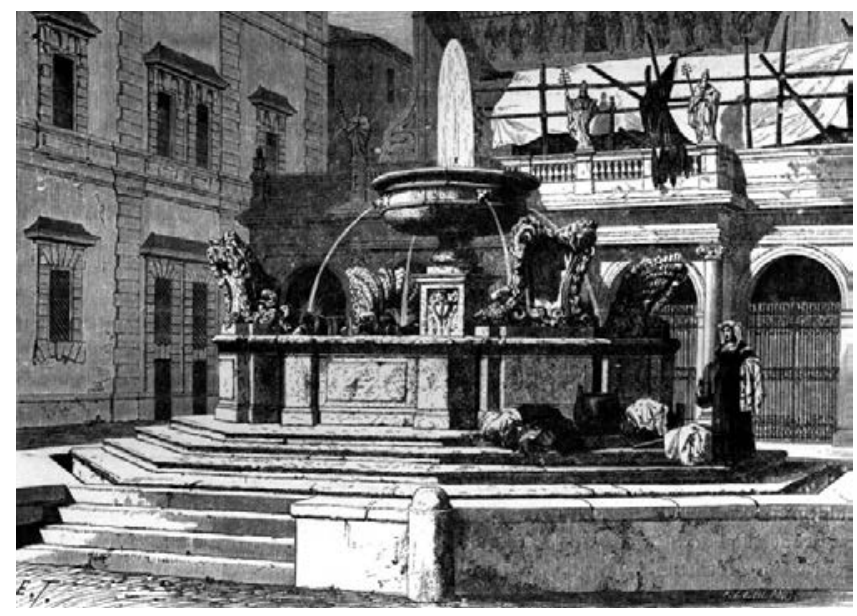

FIGURA 6

Fuente de la Piazza Santa Maria in Trastevere (Roma). Restaurada por el cardenal Joan Llopis en fechas próximas al jubileo de 1500. Fotografía: dominio público

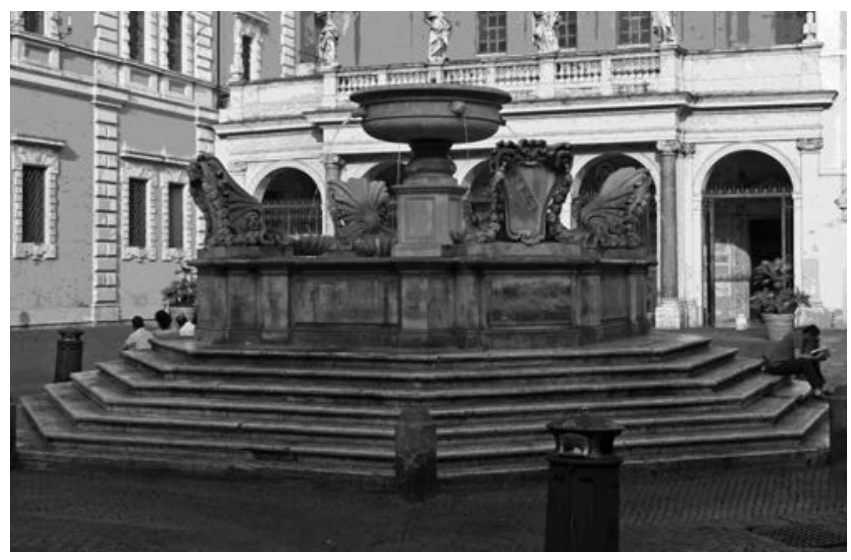

FIGURA 7

Detalle de la Fuente de la Piazza Santa Maria in Trastevere (Roma). Una de las cuatro cabezas de lobo que decoran la bandeja inferior de la fuente con el animal emblemático del cardenal Joan Llopis

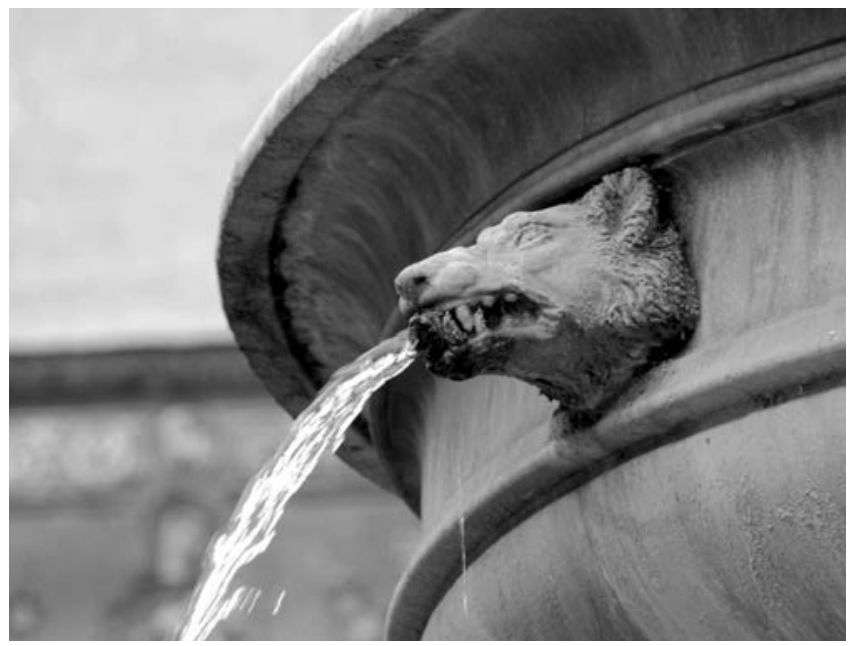

Hispania Sacra, LXIX 139, enero-junio 2017, 133-148, ISSN: 0018-215X, doi: 10.3989/hs.2017.009 
ofrecía a la ciudad de Roma el gracioso don del agua. ${ }^{139}$ Otra inscripción alusiva afirma que la fuente fue nuevamente restaurada por Julio II en 1509 , permaneciendo la taza y el balaustre de la antigua obra reformada por Llopis.

No sabemos mucho del palacio romano del cardenal que, tras su fallecimiento, fue adquirido por el cardenal Hipólito d'Este. Las labores en su residencia de Perugia inducen a pensar en una análoga preocupación, sin olvidar su posible mediación en la intervención de Bramante en el diseño del palacio de su secretario, el protonotario Adriano Caprini, en la via Alessandrina abierta con motivo del jubileo del $1500 .{ }^{140} \mathrm{La}$ ciudad de Valencia también se benefició de su influencia, pues obtuvo del papa la bula para la creación del Estudio General otorgada en $1500 ;{ }^{141}$ un año antes de que la catedral levantina recibiera del cardenal un paño de brocado de oro con sus armas dibujadas («un drap de brocat d'or fi, negre, ab vidaures de vellut vert e armes del dit reverendissimo señor cardenal») con la condición de que se usara en la fiesta de San Agustín y de San Bartolomé, la fiesta de todos los Santos y cualquiera actos de sepultura celebrados en la capilla (28.V.1501). ${ }^{142}$

A estas inquietudes artísticas habría que añadir sus contactos con humanistas y escritores como Antonio Flaminio Siculo (Antonius Biaxander), astrónomo siciliano y profesor del Studium Urbis, que le dedicó unos versos celebrando la "ingens virtus" del Lupo cardinali, que gobierna prudentemente el vasto orbe desde Roma. ${ }^{143}$ Como en los dísticos de la fontana del Trastévere, o la dedicatoria de la Vita Senecae, el eclesiástico valenciano se sitúa en el centro de la recuperación clásica del humanismo romano gracias a la asociación con la legendaria loba del Tíber; un animal célebre por su astucia y lealtad, cuyas propiedades pudo conocer el cardenal al solicitar a la Biblioteca Vaticana el De proprietatibus animalium (De Natura Animalium) del griego Claudio Eliano (ca. 175-ca. 235): ${ }^{144}$ una colección de curiosas historias con lecciones morales o alegóricas sobre animales y otros elementos naturales donde se describe la taimada fiereza del lobo, tan adecuada al carácter discreto y vigilante del antiguo datario que gustaba identificarse con el lobo pasante -no el agresivo rampante- que muestra sus fauces abiertas (dientes y lengua) en un gesto intimidatorio reconocible en la fuente del Trastévere o en sus escudos de Pieve del Vescovo.

Llopis fue testigo de la crispación internacional que dominó los últimos años del pontificado Borja. En el escenario diplomático, asumió las frágiles relaciones con Federico de Nápoles, temeroso de las pretensiones francesas sobre el Reame y del distanciamiento de Alejandro VI por influencia de César. El cardenal administró los últimos sacramentos a Alfonso de Aragón, asesinado por éste último (15.

139 Cassio 1756, I: 366-367; Pietrangeli (dir.) 1980, XIII, parte II: 122-124.

140 Lanciani 2006: 202. Sobre los cargos de "Adrianus de Caprinis", clérigo de Viterbo, que fue collector taxe plumbi, sollicitator (1502), y secretario del colegio cardenalicio (1503); Frenz 1989: n. 911.

141 Belenguer Cebrià 2011: 662.

142 Archivo de la Catedral de Valencia (Valencia), Leg. 3688, prot. de Jaume Esteve, cuaderno 2 (carpetas del genealogista Lluís Cerveró en el Archivo del Reino de Valencia).

143 El poema de Antonio Flaminio Siculo se halla en Biblioteca Apostolica Vaticana (Ciudad del Vaticano), Vat. Lat. 2870, fol. 29r (sus primeros versos se recogen en Vattaso 1900: 30 (n. 122).

144 El manuscrito fue adqurido por el cardenal en 15.XII.1498 y devuelto el 8.II.1499; cfr. Bertola 1942: 67.
VII.1500), ${ }^{145}$ y recibió las misteriosas cartas «de grandissima inportantia» que le envió su viuda, Lucrecia Borja, desde su retiro en Nepi (X/XI.1500) sobre ciertos temas relacionados probablemente con un proyecto matrimonial que debía tratar con el papa. ${ }^{146}$

A pesar del distanciamiento, los Reyes Católicos continuaron solicitando su ayuda en pequeñas gestiones, como la obtención de una reserva beneficial de 500 ducados en Cerdeña para Jerónimo de Monpalau -hijo del alcalde de Cagliari- (30.III.1499), la petición de ciertos beneficios para Juan de Rebolledo -capellán de la reina de Nápoles- o la protección del obispo de Palermo para poder reformar su diócesis (11.V.1499). Como mediador en las delicadas relaciones hispano-pontificias, Llopis informaba a los reyes en enero de 1500 de los acuerdos firmados en Roma por los embajadores ingleses y franceses, intentaba disipar sus recelos hacia César Borja asegurándoles su fidelidad a cambio de mercedes, y les aconsejaba otorgar a Pere Lluis de Borja-Llançol el arzobispado de Valencia y la abadía de Valldigna -vacantes tras el fallecimiento de su hermano Joan- que los reyes cedieron para obtener la dispensa matrimonial de María y Manuel de Portugal (18.I.1500). ${ }^{147}$ En el mes de agosto el embajador Luis de Portocarrero le manifestó la alegría de sus soberanos por su recuperación del accidente sufrido junto al papa, comunicándole «cuán encargados se tenían de él en cuantas cosas suyas acá se ofrecían» (28.VIII.1500). ${ }^{148}$

Capua había llegado a la cima de su privanza. El embajador veneciano le describe como el hombre que «está siempre junto al papa, sabe lo que quiere el papa y conoce todos sus secretos» (28.IX.1500). ${ }^{149}$ Guicciardini afirma que no sólo formaba parte de los cardenales "amicissimi et e congiuntissimi" de Alejandro VI, sino de sus "utilissimi e fidatissimi ministri», junto a Giovanni Battista Ferrari, cardenal de San Crisógono. ${ }^{150}$ En la esfera internacional, vigiló las negociaciones con Luis XII, y en el mes de octubre comunicó a los Reyes Católicos «que el Papa ofrece yr en persona a la empresa del turcho yendo el Rey de Francia, y que con este color solicita la empresa y verse con el Rey de Francia» (22.X.1500). ${ }^{151}$ No es de extrañar que celebrara la Misa de la Liga firmada por el papa para el reparto del reino de Nápoles, ni que Manuel de Portugal recurriera a sus servicios en el verano de $1501 .^{152}$

El papa se sirvió de su antiguo datario para restablecer las relaciones con otros purpurados. En noviembre le envió a parlamentar con el cardenal Colonna -enfrentado con el papa por su relación con los Orsini-, y al mes siguiente con Monreal -Joan de Borja i Navarro- distanciado entonces por la política antiaragonesa del pontífice.

145 Zurita 1996, II: 168; Cruselles Gómez 1995: 248-249; De Frede 2006: 275.

146 Gregorovius 2008: 418; Bradford 2005: 102-104 y 131-132.

147 Carta de Joan Llopis a los Reyes Católicos, 18 enero 1500; en Woodward 2005: 381-382.

148 Suárez Fernández 2002, VI: 155-156.

149 Véase el despacho del embajador veneciano Paolo Capello, 28 septiembre 1500; en Albèri (ed.) 1846, Serie II, vol. III: 6.

150 Guicciardini 1919: 82.

151 Despacho de Juan Claver a los Reyes Católicos con algunos párrafos en cifra (22.X.1500); Archivo General de Simancas (Valladolid), Estado, Leg. 496, fol. 7r-9r.

152 Silva 1862 : 5 y 13-14. 
Mientras tanto el cardenal de Capua no abandonó los asuntos españoles. En 1501 gestionó la concesión de la bula de cruzada destinada a la guerra contra los turcos, a la que él mismo aportó la modesta cantidad de 1.000 ducados en concepto de décima, que no se ajustaban a la cantidad real de sus ingresos que ascendían a 25.000 ducados sin contar las rentas de Capua. ${ }^{153}$

En 1501 le toco ocupar el cargo de camarlengo del colegio cardenalicio y -tras el fallecimiento del cardenal Zeno (7.V) - el papa le nombró arcipreste de la basílica de San Pedro (10.V) con la idea de ponerle al frente de la Capilla Pontificia. ${ }^{154}$ No hubo tiempo para tanto. Aquel verano Llopis comenzó a sufrir los síntomas de la enfermedad que acabó con su vida el 5 de agosto en sus apartamentos del Vaticano, tras entregar todos sus bienes al papa. Pronto surgieron los rumores de envenenamiento. ${ }^{155} \mathrm{El}$ embajador veneciano conjeturó que "sia stato atossichato" debido a los escasos diez días que duró la enfermedad, y había quien sospechaba del propio Alejandro VI por haberse distanciado del cardenal durante su convalecencia. Según este rumor, Llopis guardaba demasiados secretos que convenía sepultar, pues al papa «no li pareva cosa secura hora mai li sapesse altro vivente che lui». ${ }^{156}$ Otros atribuyeron su muerte al veneno de César Borja, receloso de este confidente que manejaba «los asuntos del papado más de lo conveniente». Sin embargo, no parece que el cardenal fuera «poco amigo del gran Vexillifero» si tenemos en cuenta su apoyo ante los Reyes Católicos, los agasajos que le dispensó a su vuelta de la Romagna (26.II.1500), o los fuegos encendidos en su palacio para celebrar la conquista de Faenza (27.IV.1501).

El maestro de ceremonias Johannes Burckardt, que siguió con detalle sus dolencias, no consideró sospechosa su muerte (5.VIII.1501), aunque advirtió la premura con que fue colocado en un sepulcro de mármol junto a su paisano Bartomeu Martí, en la capilla de Santa Maria della Febbre de la basílica vaticana (Capella Santi Apostoli Andrea e Giacomo), donde se hallaban los restos de Calixto III y más tarde yacerán los de Alejandro VI. ${ }^{157}$ En las exequias celebradas diez días después, Bartolomé Florentino levantó un elegante castrum doloris y fue convocado todo el colegio cardenalicio y el cuerpo diplomático, incluido el embajador Francisco de Rojas. El papa quiso honrar de esta forma a quien fue «la más acepta persona que tenía para el gobierno de los negocios de estado». ${ }^{158}$ Los Llopis perdían así a su miembro más destacado sin beneficiarse de su prestigiosa carrera pues el papa reclamó los bienes de los cardenales difuntos, recuperando una práctica fiscal en desuso que neutralizaba cualquier intento de crear patrimonios familiares con los bienes eclesiásticos. Por ello, como señala Cruselles Gómez, la desaparición de Joan y de Francesc Gasset cerró el futuro italiano de aquella familia que debió replegarse a sus bases valencianas. ${ }^{159}$

153 Así lo indica Vespucci el 25 de agosto de 1501; Machiavelli 1995: 457-458; AA.VV. 1936: 119.

154 Reynolds 1995: 56; Rezza y Stocchi 2008: 214 y ss.

155 Chacón 1677: 186.

156 Fabbri 2006: 67-68.

157 Burckardt 1907-1942, II: 289.

158 Zurita 1996, II: 154.

159 Cruselles Gómez 1996: 250-253.

\section{CONCLUSIONES}

A la vista de estas líneas, la figura de Joan Llopis se sitúa entre los discretos y eficaces servidores de Alejandro VI. A pesar de sus humildes orígenes y gracias a los vínculos clientelares, protagonizó una fulgurante carrera eclesiástica que pudo beneficiar a determinados miembros del clan sin cristalizar en un patrimonio eclesiástico familiar como en tiempos de Calixto III. Su cuidada educación en Valencia y Bolonia le proporcionó la formación necesaria para ascender en la cancillería y cultivar la amistad de humanistas del círculo romano del vicecanciller (Paolo Pompilio, Jeroni Pau, Michele Ferno) o del Studium Urbis (Antonio Flaminio Siculo); y sus contactos con artistas como Perugino o Donato Bramante manifiestan su sensibilidad artística y su capacidad de integración en el ambiente mecenático de la Roma papal.

En su iter curial la ocupación del oficio de la dataría y el acceso al capelo cardenalicio constituyeron dos sólidas plataformas para asegurar su posición junto a un papa que basculaba hacia un gobierno personalista ante la ausencia de apoyos en el colegio de cardenales. La discreción y fidelidad de Llopis fueron sus credenciales para ganarse la confianza de Alejandro VI y permanecer en la escena cortesana a pesar de la inestabilidad política. A diferencia de otros familiares borgianos, Llopis logró salir del círculo doméstico entablando relaciones con la Florencia de los Medici, el Milán de los Sforza, el Nápoles aragonés y la corte de los Reyes Católicos. Una versatilidad diplomática y cortesana que compartió con Joan de Borja-Llançol y, en cierta medida con Jaume Serra, logrando salvar los momentos de crisis favoreciendo los intereses pontificios. ${ }^{160}$ La privanza papal le permitió ascender a cotas difícilmente igualadas por otros cardenales pero también le impuso ciertos límites de acción, supeditando su actividad a los intereses políticos y familiares de Alejandro VI, sin logar establecer vínculos sólidos con la natio hispana y los grupos aristocráticos eclesiásticos o seculares de la península ibérica e italiana.

Su complicidad con Alejandro VI y su intervención en su gobierno le convierten en una especie de "ministro de interior" o cardenal secretario de Estado avant la lettre, cuyas prerrogativas parecen emanar de las fisuras generadas entre el romano pontífice y buena parte del colegio cardenalicio. ${ }^{161}$ Gracias a ello, Llopis supo moverse por los escenarios de la alta política como servidor del papa ante los príncipes italianos y los Reyes Católicos, sin crear una base autónoma de sostenimiento, o garantizar una plataforma de promoción para su familia, que sólo pudo beneficiarse de su protección durante su privanza. La acumulación de tanto poder y la ambigüedad de su gestión suscitaron críticas centradas en la acumulación de beneficios y la corrupción; una lacra que arruinó a algunos curiales borgianos como el procesado Bartolomeo Flores, pero no afectó a otros, como el cardenal Joan de Vera. ${ }^{162}$ Son las luces y las sombras de aquella generación de valencianos que empeñaron vidas y fortunas al servicio del papado en uno de los momentos más convulsos de su historia.

160 Sobre estos personajes cfr. Pons Alós 2005: 84-86 y 88-92; Navarro Sorní 2010; Goñi Gaztambide 1975, IV: 2438-2439; Batllori 1986, 21: 93; Fernández de Córdova Miralles, Á. El cardenal Jaume Serra (en preparación).

161 Richard 1910.

162 Cfr. Giordano 1997; Fernández de Córdova Miralles, Á. 2013b. 


\section{FUENTES}

Biblioteca Apostolica Vaticana (Ciudad del Vaticano). Archivio Secreto Vaticano (Ciudad del Vaticano). Archivio di Sato di Firenze (Florencia).

Archivo Histórico Nacional (Madrid).

Archivo de los Condes de Cedillo (Madrid).

Archivo del Reino de Valencia (Valencia).

Archivo General de Simancas (Valladolid).

Biblioteca del Seminario Diocesano (Gerona).

Biblioteca Comunale Augusta di Perugia (Perugia).

\section{BiBLIOGRAFÍA}

AA. VV. 1936. «Essai de liste générale des cardinaux. VIII. Les cardinaux du XVI ${ }^{e}$ siècle». Annuaire Pontifical Catholique.

Abbozzo, F. y Tiroli, A. (dir.) 2004. Perugino, pittore devozionale: modelli e riflessi nel territorio di Corciano. Milán: Silvana.

Albèri, E. (ed.) 1846. Relazioni degli ambasciatori veneti al Senato. Serie II. Florencia: Società editrice fiorentina.

Altieri, M. A. 1995. Li Nuptiali di Marco Antonio Altieri pubblicati da Enrico Narducci, ed. de M. Miglio y A. Modigliani. Roma: Roma ne Rinascimento.

Baglioni, A. 1845. Città della Pieve illustrata lettere storiche di Antonio Baglioni. Montefiascone: Tipografia del Seminario.

Batllori, M. (ed.) 1986. «Serra, Jaume», en Gran Enciclopèdia Catalana, vol. 21: 93. Barcelona: Enciclopèdia Catalana.

Batllori, M. (ed.) 1998. De València a Roma. Cartes triades dels Borja. Barcelona: Quaderns Crema.

Belenguer Cebrià, E. (ed.) 2011. Col-lecció documental del regnat de Ferran Il i la ciutat de València (1479-1516). Valencia: Fundació Noguera.

Bellonci, M. 1939. Lucrezia Borgia e i suoi tempi, Verona: Mondadori.

Benavent, J. 2005. «Relaciones universitarias en Europa y poder político en los siglos XV y XVI"), en Viajar para saber. Movilidad y comunicación en las universidades europeas: 159-170. Valencia: Universitat de València.

Benavent, J. (ed.) 2007. Biblioteca dispersa: manuscrits i Incunables Valencians dels segles XIV al xvii. Valencia: Goaprint.

Bertola, M. 1942. I due primi registri di prestito della Biblioteca apostolica vaticana, codici vaticani latini. 3964, 3966. Ciudad del Vaticano: Biblioteca Apostólica Vaticana.

Borràs i Feliu, A. 1984. "Principales fondos concernientes a la última fase del reino de Sicilia-Nápoles, conservadas en el Arxiu del Palau de Barcelona», en Actas del IX Congreso de Historia de la Corona de Aragón: La Corona de Aragón y el Mediterráneo. Aspectos y problemas comunes desde Alfonso el Magnánimo a Fernando el Católico (1416-1516): 19-47. Zaragoza: Institución Fernando el Católico.

Bracke, W. 2002. "Paolo Pompilio, una carriera mancata», en D. Canfora, M. Chiabò, y M. de Nichilo (dirs.), Principato ecclesiastico e riuso dei classici. Gli umanisti e Alessandro VI (Bari-Monte Sant'Angelo, 22-24 maggio 2000): 429-438. Roma: Ministero per i Beni e le Attività Culturali.

Bradford, S. 2005. Lucrecia Borgia. Madrid: Planeta.

Bruschi, A. 1987. Bramante. Bilbao: Xarait Ediciones.

Burckard, J. 1883. Diarium sive Rerum urbanarum commentarii (14831506), ed. de Thuasne. París: Leroux.

Burckard, J. 1907-1942. Liber notarum ab anno 1483 usque ad annum 1506, ed. E. Celani. Città di Castello: Editrice S. Lapi.

Campanus, J. A. 1929. Braccii Perusini vita et gesta, ed. Roberto Valentini, Rerum Italicarum Scriptores. 19/4. Bolonia: Lapi/ Zanichelli.

Cantatore, F. 2007. San Pietro in Montorio: la chiesa dei Re Cattolici a Roma. Roma: Quasar.

Cardella, L. 1793. Memorie storiche de' cardinali della santa Romana Chiesa. Roma: Stamperia Pagliarini.
Casagrande, G. y Monacchia, P. 2001. "Colomba da Rieti di fronte ad Alessandro Vl», en M. Chiabò, S. Maddalo y M. Miglio (dirs.), Roma di fronte all'Europa al tempo di Alessandro VI. Atti del Convegno (Città del Vaticano-Roma, 1-4 dicèmbre 1999), vol. III: 917-951. Roma: Ministero per i Beni e le Attività Culturali.

Cassio, A. 1756. Corso dell'acque antiche portate da lontane contrade fuori e dentro Roma. Roma: Stamperie Giannini.

Célier, L. 1910. Les Dataires du Xve siècle et les origines de la Datarie apostolique. París: Fontemoing.

Ceresa, M. 1996. «Ferno, Michele», en Dizionario Biografico degli Italiani, vol. 46: 359-361. Roma: Istituto della Enciclopedia Italiana.

Chabàs, R. 1893. «Alejandro VI y el Duque de Gandía. Estudios sobre documentos valencianos». El archivo 7: 85-139.

Chacón, A. 1677. Vitae et res gestae Pontificum romanorum et S.R.E. Cardinalium. Roma: Typis Vaticanis.

Clement, A. 1882. Les Borgia: histoire du pape Alexandre VI, de César et de Lucrèce Borgia. París: St Paul.

Company, X. 2002. Alexandre VI i Roma. Les empreses artistíques de Roderic de Borja a Itália. Valencia: Tres i Quatre.

Cordero, F. 1988. Savonarola, vol. IV: Agonista perdente (1497-98). Roma: Laterza.

Cruselles Gómez, J. M. 1986. «Familia y promoción social: los Lopiç de Valencia (1448-1493)». Estudis Castellonencs 3: 355-380.

Cruselles Gómez, J. M. 1992a. "Valencianos en la universidad de Bolonia: rentabilización social de los estudios superiores a fínales del siglo XV», en Lluís de Santángel i el seu temps: 387-400. Valencia: Generalitat Valenciana.

Cruselles Gómez, J. M. 1992b. "Los juristas valencianos en la Italia renacentista. Estudiantes y cortesanos». Revista d'Història Medieval 3: 143-160.

Cruselles Gómez, J. M. 1995. «El cardenal de Capua», en R. Narbona et alii (ed.), L'univers dels prohoms: 217-256. Valencia: Eliseu Climent.

Cruselles Gómez, J. M. 1997. "Valencianos en la Universidad de Bolonia: rentabilización social de los estudios superiores a finales del siglo XV», en Lluís de Santàngel i el seu temps: 387-400. Valencia: Ajuntament de València.

Cruselles Gómez, J. M. 1998. Els notaris de la ciutat de València. Activitat professional $i$ comportament social a la primera meitat del segle XV: 175-188. Barcelona: Pagés Editors.

Cruselles Gómez, J. M. 2001. «El cardenal Rodrigo de Borja, los curiales romanos y la política eclesiástica de Fernando II de Aragón», en E. Belenguer Cebrià (dir.), De la unión de coronas al Imperio de Carlos V. Congreso Internacional (Barcelona, 21-23 febrero 2000), vol. I: 253-279. Barcelona: Sociedad Estatal para la Conmemoración de los Centenarios de Felipe II y Carlos V.

Cruselles Gómez, J. M. 2008-2009. «La clientela borgiana en los archivos notariales valencianos». Revista Borja. Revista de I'IIEB, 2: 187190. [http://www.elsborja.org/revista.php].

Cruselles Gómez, J. M. e Igual Luis, D. 2005. El duc Joan de Borja a Gandia. Els comptes de la banca Spannochi (1488-1496). Gandía: Centre d'Estudis i Inv. Comarcals Alfons el Vell.

Cruselles Gómez, J. M. e Iradiel, P. 2001. «El entorno eclesiástico de Alejandro VI. Notas sobre la formación de la clientela política borgiana (1429-1503)", en M. Chiabò, S. Maddalo y M. Miglio (dirs.), Roma di fronte all'Europa al tempo di Alessandro VI. Atti del Convegno (Città del Vaticano-Roma, 1-4 dicèmbre 1999), vol. I: 27-58. Roma: Ministero per i Beni e le Attività Culturali.

Cruselles Gómez, J. M. y Navarro Sorní, M. 2012. «López, Juan. Joan Llopis», en Diccionario Biográfico Español, vol. 30: 252-254. Madrid: Real Academia de la Historia.

D’Auton, J. 1891. Chroniques, ed. M. A. R. de Maulde la Clavière. París: Librairie Renouard.

D’Onofrio, C. 1962. Le Fontane di Roma: con documenti e disegni inediti. Roma: Staderini.

De Berzeviczy, A. 1911-1912. Béatrice d'Aragon reine de Hongrie (1457-1508). París: H. Champion.

De Frede, C. 2006. «Nella Roma borgiana: I'assassinio del Duca di Bisceglie narrato dall'umanista Raffaele Brandolini», en Manoscritti, editoria e biblioteche dal medioevo all'età contemporanea: studi 
offerti a Domenico Maffei per il suo ottantesimo compleanno: 259280. Roma: Roma nel Rinascimento.

Desjardins, A. 1859. Négotiations diplomatiques de la France avec la Toscane. París: Imprimerie Impériale.

Fabbri, R. 2006. "Spiriti antiborgiani in scritture veneziane coeve», en P. Iradiel, y J. M. Cruselles (dirs.). 2006. De València a Roma a través dels Borja: 53-68. Valencia-Roma: Generalitat ValencianaMinistero-Roma nel Rinascimento.

Faider, P. 1921. "Paulus Pompilius, Vita Senecae», en P. Faider, Études sur Sénèque Études sur Sénèque: 281-282. Gante: Van Rysselberghe \& Rombaut.

Fernández Alonso, J. 1956. «Las iglesias nacionales de España en Roma. Sus orígenes». Anthologica Annua, 4: 9-96.

Fernández de Córdova Miralles, Á. 2005a. Alejandro VI y los Reyes Católicos. Relaciones político-eclesiásticas (1492-1503). Roma: Edizioni Università della Santa Croce.

Fernández de Córdova Miralles, Á. 2005b. «Imagen de los Reyes Católicos en la Roma pontificia». En la España Medieval 28: 259-354.

Fernández de Córdova Miralles, Á. 2007a. «Alejandro VI y los Reyes Católicos. Afinidades y diferencias al final de un pontificado (14981503)», en La llum de les imatges, Libro de Estudios: 281-299. Valencia: Generalitat Valenciana.

Fernández de Córdova Miralles, Á. 2007b. «Reyes Católicos: mutaciones y permanencias de un paradigma político en la Roma del Renacimiento», en C. J. Hernando Sánchez (coord.), Roma y España. Un crisol de la cultura europea en la Edad Moderna, Actas del Congreso Internacional celebrado en Real Academia de España en Roma del 8 al 12 de mayo de 2007: 133-154. Madrid: Sociedad Estatal para la Acción Cultural Exterior.

Fernández de Córdova Miralles, Á. 2009. «Cèsar Borja en el seu context històric: entre el pontificat i la monarquia hispànica», en Á. Fernández de Córdova Miralles, J. Arrizabalaga, y M. Toldrà, Cèsar Borja cinc-cents anys després (1507-2007). Tres estudis i una antología: 11-98. Valencia: Tres i Quatre.

Fernández de Córdova Miralles, Á. 2012. "Martí, Bartolomé», en Diccionario Biográfico Español, vol. 32: 730-732. Madrid: Real Academia de la Historia.

Fernández de Córdova Miralles, Á. 2013a. "Las empresas del cardenal Lluís Joan del Milà. Promoción eclesiástica y mecenazgo entre Italia y el reino de Aragón». Aragón en la Edad Media 24: 191-223.

Fernández de Córdova Miralles, Á. 2013b. "Vera, Juan de», en Diccionario Biográfico Español, vol. 49: 669-671. Real Academia de la Historia: Madrid.

Fernández de Córdova Miralles, Á. (2014a). «Diplomáticos y letrados en Roma al servicio de los Reyes Católicos: Francesco Vitale di Noya, Juan Ruiz de Medina y Francisco de Rojas». Dicenda: Cuadernos de filología hispánica 32: 113-154.

Fernández de Córdova Miralles, Á. 2014b. «La emergencia de Fernando el Católico en la Curia papal: identidad y propaganda de un príncipe aragonés en el espacio italiano (1469-1492)», en A. Egido Martínez y J. E. Laplana Gil (dir.), La imagen de Fernando el Católico en la historia, la literatura y el arte, II Jornadas Fernandinas: 29-82. Zaragoza: Institución "Fernando el Católico".

Figliuolo, B. 2015. Corrispondenza degli ambasciatori fiorentini a Napoli, VIII. Inviati diversi (giugno 1493-ottobre 1494). Salerno: Laveglia.

Forcella, V. 1879. Iscrizioni delle chiese e d'altri edificii di Roma dal secolo XI fino ai giorni nostri. Roma: Tip. delle scienze matematiche e fisiche.

Fragnito, G. 1993. "Cardinals' Courts in Sixteenth-Century Rome». Journal of Modern History, 65: 26-56.

Frenz, Th. 1989. Die Kanzlei der Papste der Hochrenaissance (14711527). Roma: Niemeyer.

Fumi, L. 1877. Alessandro VI e il Valentino in Orvieto. Siena: L. Lazzeri.

Gairdner, J. 1861. Letters and papers illustrative of the reigns of Richard III and Henry VII. Londres: Longman.

Galli, L. 2001. Una pieve tra i monti. Itinerario storico artistico del Castello di Pieve del Vescovo. Perugia: Edilprom.
Garcilaso de la Vega (ed.) 1842. Carta a los Reyes Don Fernando y Doña Isabel de su embajador en Roma en 1498. San Sebastián: Imprenta de Ignacio Ramón Baroja.

Giordano, S. 1997. "Florido (Flores, Floridus), Bartolomeo», en Dizionario Biografico degli Italiani, vol. 48: 342-343. Roma: Istituto della Enciclopedia Italiana.

Goñi Gaztambide, J. 1975. "Serra, Jaime», en Q. Aldea Vaquero, T. Marín Martínez y J. Vives Gatell, Diccionario de Historia Eclesiástica de España, vol. IV: 2438-2439. Madrid: Instituto Enrique Flórez.

Goñi Gaztambide, J. 1987. «López, Juan», en Q. Aldea Vaquero, T. Marín Martínez y J. Vives Gatell, Diccionario de Historia Eclesiástica de España, Suplemento: 439-440. Madrid: Instituto Enrique Flórez.

Grafinger, Ch. M. 2002. Die Ausleihe vatikanischer Handschriften und Druckwerke, 18. Jahrhundert. Città del Vaticano: Biblioteca apostolica vaticana.

Gregorovius, F. 2008. Lucrecia Borja a partir de documents i epistolaris del seu temps, ed. de M. Toldrà. Valencia: Tres i Quatre.

Gualdo Rosa, L. 2009. "Le strane vicende di Seneca nelle biografie umanistiche da Gasparino Barzizza a Erasmo, con qualche eccezione alla scuola di Pomponio Leto», en Syntagmatia. Essays on neo-latin literature in honour of Monique Mund-Dopchie and Gilbert Tournoy: 19-32. Leuven: Leuven University Press.

Guicciardini, F. 1919. Storia d'Italia. ed. Alessandro Gherardi. Florencia: G. C. Sansoni.

Ilari, A. 2001. "Appendice: i familiari di Alessandro VI», en en M. Chiabò, S. Maddalo y M. Miglio (dirs.), Roma di fronte all'Europa al tempo di Alessandro VI. Atti del Convegno (Città del VaticanoRoma, 1-4 dicèmbre 1999), vol. I: 249-321. Roma: Ministero per i Beni e le Attività Culturali.

Kibre, P. 1936. The Library of Pico della Mirandola. New York: Columbia University.

Lanciani, R. 2006. L'epoca d'oro del Rinascimento a Roma. Roma: Newton \& Compton.

López Arandia, M. A. 2005. «Castellanos y curia romana a inicios del siglo XVI: Gutierre González». Dimensioni e problemi della recerca storica 2: 55-87.

Machiavelli, N. 1995. Epistolario 1512-1527, ed. S. Mastrangelo. México: Fondo de Cultura Económica.

Mancini, F. F. 2003. Pieve del Vescovo: una residenza fortificata nel territorio di Perugia. Perugia: Edilprom.

Marchese, V. 1850. «Documenti intorno alla vita e la morte di Girolamo Savonarola». Archivio storico italiano 8: 147-149.

Marías, F. 1987. «Bramante en España», en A. Bruschi, Bramante: 7-67. Bilbao: Xarait Ediciones.

Martín Martín, J. L. 1989. Documentación medieval de la Iglesia Catedral de Coria. Salamanca: Ediciones Universidad.

Menotti, M. 1917. Documenti inediti su la famiglia e la corte di Alessandro VI: vol. II. Roma: Tipografia dell'Unione editrice.

Minnucci, G. 1981. Le lauree dello Studio Senese alla fine del xV secolo. Milán: Giuffré.

Minnucci, G. y Kosŭta, L. 1989. Lo Studio di Siena nei secoli XIV-XVI: documenti e notizie biografiche. Milán: Giuffré.

Moroni, G. 1843. Dizionario di erudizione storico-ecclesiastica. Venecia: Tipografia Emiliana.

Mozzarelli, C. (ed.). 1988. "Familia" del principe e famiglia aristocrática. Roma: Bulzoni.

Navarro Sorní, M. 2010. "Borja-Llançol de Romaní y de Moncada», en Diccionario Biográfico Español, vol. 9. Real Academia de la Historia: Madrid.

Navarro Sorní, M. y Fernández de Córdova Miralles, Á. 2009. «Alejandro VI. Rodrigo de Borja», en Diccionario Biográfico Español, vol. II: 555-565. Real Academia de la Historia: Madrid.

Núñez, L. M. 1916. «Dos cartas interesantes de Fray Bernardo Boil a Cisneros». Archivo Ibero-Americano 6: 433-443.

Oliver y Hurtado, M. 1896. «Don Rodrigo de Borja (Alejandro VI). Sus hijos y descendientes». Boletín de la Real Academia de Historia 9: 402-447.

Ortí y Belmonte, M. Á. 1958. Episcopologio cauriense. Cáceres: Diputación Provincial. 
Parisi, I. 2006-2007. «Il regesto dei protocolli del notaio Camillo Beneimbene: I volumi nn. 175 e 176 del fondo del Collegio de Notai Capitolini dell'Archivio di Stato di Roma». Revista Borja. Revista de l'IIEB I: 139-276.

Parisi, I. (ed.) 2015. Diplomatari Borja 5: Archivio di Stato de Roma: Documents dels protocols de Camillo Beneimbene (1479-1505), edición y estudio a cargo de Ivan Parisi. València: Tres i Quatre.

Partner, P. 1990. The Pope's Men. The Papal Civil Service in the Renaissance. Oxford: Clarendon Press.

Partner, P. 2003. «La Camera apostolica come organo centrale delle finanze pontificie», en C. Frova y M. G. Nico Ottaviani (dirs.), Alessandro VI e lo Stato della Chiesa. Atti del Convegno (Perugia, 13-15 marzo 2000): 27-36. Roma: Ministero per i Beni e le Attività Culturali.

Pastor, L. von. 1942. Storia dei Papi dalla fine del Medioevo, vol. III: Storia dei Papi nel periodo del Rinascimento dall'elezione di Innocenzo VIII alla morte di Giulio II. Roma: Desclée.

Pelissier, L. G. 1898. "Sopra alcuni documenti relativi all'alleanza tra Alessandro VI e Luigi XII (1498-1499)». Archivio della società romana di storia patria 18: 303-374.

Pellegrini, M. 2002a. Ascanio Maria Sforza. La parabola politica di un cardinale-principe del Rinascimento. Roma: Istituto Storico Italiano per il Medio Evo.

Pellegrini, M. 2002b. «A turning-point in the history of the factional system in the Sacred College: the power of pope and cardinals in the age of Alexander VI», en G. Signorotto y M. A. Visceglia (dirs.), Court and politics in papal Rome, 1492-1700: 8-30. Cambridge: Cambridge University Press.

Pellegrini, M. 2005. "Tra ragione e azzardo. La secolarizzazione de cardinale Valentino», en M. Bonvini Mazzanti y M. Miretti (ed.), Cesare Borgia di Francia gonfaloniere di Santa Romana Chiesa 1498-1503. Conquiste effimere e progettualità statale (Urbino 4-5-6 dicembre 2003): 47-71. Ostra Vetere: Tecnostampa Edizioni.

Picotti, G. B. 1927. La giovinezza di Leone X. Milán: Editore Ulrico Hoepli.

Pietrangeli, C. (dir.) 1980. Guide rionali di Roma. Rione XIII. Trastevere. Roma: Fratelli Palombi Editori.

Pocino, W. 2002. Le fontane di Roma. Roma: Newton \& Compton.

Pons Alós, V. 2005. Cardenales y prelados de Xativa en la epoca de los Borja. Xativa: Centro de Estudios Borgianos.

Pons Alós, V. y Cárcel Ortí, M.a M. 2001. «La diócesis de Valencia en los pontificados de los Borja». Anales Valentinos 53: 87-119.

Pons Alós, V. y Cárcel Ortí, M.a M. 2005. «Los canónigos de la catedral de Valencia (1375-1520). Aproximación a su prosopografía». Anuario de Estudios Medievales 35/2: 907-950.

Reynolds, Ch. A. 1995. Papal Patronage and the Music of St. Peter's, 1380-1513. Berkeley: University of California Press.

Rezza, D. y Stocchi, M. 2008. Il capitolo di San Pietro in Vaticano dalle origini al $x x$ secolo. Ciudad del Vaticano: Edizioni Capitolo Vaticano.

Richard, P. 1910. «Origines et développement de la secrétairerie d'état apostolique, 1417-1823», Revue d'histoire ecclésiastique 11: 56-72.

Ridolfi, R. 1981 (reed. 1997). Vita di Girolamo Savonarola. Florencia: Le Lettere.

Russo, F. 1977. «L'abbazia cistercense di S. Maria di Corazzo (Regesto di documenti)». Notizie Cistercensi 10: 77-104.

Salvador Miguel, N. 2012. «Intelectuales españoles en Roma durante el gobierno de los Reyes Católicos», en Rumbos del hispanismo en el umbral del Cincuentenario de la Asociación Internacional de Hispanistas, vol. I: 47-64. Roma: Bagatto Libri.

Sanchís Sivera, J. 1919. "Algunos documentos y cartas privadas que pertenecieron al segundo duque de Gandía, don Juan de Borja. (Notas para la historia de Alejandro VI)». Anales del Instituto General y Técnico de Valencia 4: 5-152.
Sanudo, M. 1879-1903. Diarii, ed. R. Fulin. Venecia: Tipografia del commercio di Marco Vesentini.

Serio, A. 2003. «Modi, tempi, uomini della presenza hispana a Roma tra la fine del Quattrocento e il primo Cinquecento (1492-1527)», en F. Cantù, y M. A. Visceglia (dirs.), L'Italia di Carlo V. Guerra, religione e politica del primo Cinquecento. Atti del Convegno internazionale di studi (Roma, 5-7 aprile 2001): 433-476. Roma: Viella.

Signorotto, G. y Visceglia, M. A. (ed.) 1998. La Corte di Roma tra Cinque e Seicento. 'Teatro' della politica europea. Roma: Bulzoni.

Silva, L. A. Rebello da 1862. Quadro elementar das relações políticas e diplomáticas de Portugal com as diversas potências do mundo, vol. I: Relações com a Curia Romana. Reinado de D. Manuel 1501-1517. Lisboa: Academia Real das Sciencias de Lisboa.

Storti, N. 1969. La storia e il diritto della Dataria Apostolica dalle origini alle nostre giorni. Nápoles: Athena mediterranea.

Suárez Fernández, L. 1971. Política internacional de Isabel la Católica. Estudio y documentos. Valladolid: Universidad de Valladolid.

Tiroli, A. 2004. "Sculture e pitture del territorio di Corciano», en F. Abbozzo y A. Tiroli (dir.), Perugino, pittore devozionale: modelli e riflessi nel territorio di Corciano: 55-78. Milán: Silvana.

Torre y del Cerro, A. de la 1921. «La colección sigilográfica del Archivo de la Catedral de Valencia». Archivo de Arte Valenciano 7: 103-110.

Torre y del Cerro, A. de la 1962. Documentos sobre las relaciones internacionales de los Reyes Católicos, vol. IV. Barcelona: Consejo Superior de Investigaciones Científicas.

Trinchera, F. (dir.). 1868. Codice Aragonese ossia lettere regie, ordinamenti ed altri atti governativi dei sovrani aragonesi in Napoli, vols. I-II. Nápoles: Archivio di stato.

Tubau, X. 2010. «Las alianzas a la luz del Derecho Canónico: el Tractatus Dialogicus de confoederatione principum et potentatum (c. 1495) de Juan López de Segovia». Anuario de Estudios Medievales 40: 537-563.

Uhagón y Guardamino, F. R. de (ed.) 1916. Relación de los festinos que se celebraron en el Vaticano con motivo de las bodas de Lucrecia Borja con don Alonso de Aragón. Madrid: Real Academia de la Historia.

Vaquero Piñeiro, M. 1993. "L'ospedale della nazione castigliana in Roma tra Medioevo de età moderna». Roma moderna e contemporanea 1: 57-81.

Vaquero Piñeiro, M. 1994. «Una realtà nazionale composita: comunità e chiese "spagnole" a Roma», en S. Gensini (dir.), Roma capitale (1447-1527): 473-491. Roma: Pubblicazioni degli archivi di stato.

Vaquero Piñeiro, M. 2001. "Valencianos en Roma durante el siglo XV: una presencia en torno a los Borja», en M. González Valdoví y V. Pons Alós (coords.), El Hogar de los Borja: 2000 any Borja: 185198. Valencia: Generalitat Valenciana.

Vattaso, M. 1900. Antonio Flaminio e le principali poesie dell'autografo vaticano 2870. Roma: Tipografia Vaticana.

Vilallonga, M. 1986. Jeroni Pau. Obres. Barcelona: Curial.

Vincioli, G. 1730. Notizie istorico-critiche $a^{\prime}$ ritratti di 24 cardinali perugini colla serie cronologica de' vescovi. Foligno: Campana Stampatore.

Visceglia, M. A. 2008. «Casa y servidores del Papa durante la Primera Edad Moderna», Studia historica. Historia moderna 30: 85-108.

Wilkie, W. H. 1974. The Cardinal Protectors of England: Rome and the Tudors Before the Reformation. Londres: Cambridge University Press.

Woodward, H. W. 2005. Cèsar Borja, prólogo de J. Benavent y revisión de M. Toldrà. Valencia: Tres i Quatre.

Zurita, J. 1977. Anales de la Corona de Aragón. Valencia: Anubar.

Zurita, J. 1996. Historia del rey don Hernando el Cathólico. De las empresas y ligas de Italia, ed. A. Canellas López. Zaragoza: Gobierno de Aragón. 